\title{
Influence Of Strategy Implementation On The Performance of Maritime Cluster Firms In Kenya
}

\author{
Mulama Moses Shimengah \\ Doctor of Philosophy in Strategic Management \\ Jomo Kenyatta University of Agriculture and Technology, Kenya \\ Dr. Jane Wanjiku Gathenya \\ Lecturer \\ Jomo Kenyatta University of Agriculture and Technology, Kenya \\ Professor Romanus Odhiambo Otieno \\ Lecturer \\ Jomo Kenyatta University of Agriculture and Technology, Kenya
}

\begin{abstract}
The study of strategy implementation on the performance of maritime cluster firms has not been fully exhausted for economic growth despite its vast potential resources. In recent times, many countries near the oceans, seas, lakes, rivers and dams are exploiting their natural resources both off shore and on shore (for blue economy) with an aim of increasing their competitive advantage to create employment opportunities, wealth as new frontier by implementing maritime clusters strategy for economic growth and sustainability. This process helps them strengthen their national and regional competitiveness through clustering for their industrial development through processing, manufacturing and value addition of their products. This study seeks to stir up an academic curiosity in the field of maritime academic discipline and anticipates enhancing both policy and knowledge gaps in maritime related cluster firms. The findings of the research will be of importance to policy makers within the government and the maritime cluster firms as well as contribute to the body of knowledge as a reference material for future research works. The main objective of this study is to establish the influence of strategy implementation on performance of Maritime Cluster firms in Kenya and the specific objectives of this study are to establish the influence of strategic policies, strategic direction, organization structure, resource capability, technology innovation, firms' size and years of operation on the performance of maritime cluster firms in Kenya. The research will allow collection of both quantitative and qualitative data and adopt descriptive research (statistical research) as well as inferential statistics designs in which variables of interest will not be controlled or manipulated. The target population of the study is $\mathbf{1 3 8 6}$ maritime firms and the sample size of 94 firms which will be randomly selected as a basis for unit of analysis. Thus, the study will perform a pilot test to support reliability and validity tests based on $10 \%$ of the sample size of about 10 firms out of 94 firms which will not be included in the main study sample. Both primary and secondary data will be collected by use of questionnaires, structured interviews as instrument of data collection. Both factor analysis and correlation analysis will be used to determine the magnitude and direction of the association between research variables. The study will further perform hypothesis testing using ANOVA. The quantitative data collected will be analysed further through descriptive statistics such as mean, median, standard deviation supported by the statistical package for social science SPSS version 22 whereas the qualitative data will be analysed by use thematic analysis.
\end{abstract}




\section{INTRODUCTION}

This chapter outlines the background of the research that highlights the global view as well as the local perspective on the concepts of strategy implementation and performance of maritime cluster firms to provide a deeper understanding of the place of clusters in the Kenyan Maritime sector. The problem statement, objectives of the study, research hypotheses, significance and the scope of the study are also outlined in this chapter.

\section{Background to the Study}

Globally, an estimated 61\% of the GDP in the world comes from areas within $100 \mathrm{~km}$ of the coastline maritime. More than USD 191 billion annually is derived from seafood and some USD 161 billion annually from marine, coastal tourism and over USD 300 million livelihood from fishing, aquaculture, whereas the seafloors, yield important minerals and serve as source of energy apart from the other maritime related resources extending inland according to (Rio +20 Ocean declaration, 2012). Therefore, strategy implementation presents a key process towards success in Maritime Cluster industries given the important role maritime firms play in the economy of any given country including Kenya. This is so since organizations that adopt good strategy formulation and implement them iteratively, achieve their set goals or record higher performance (Allios, 2014). Globally, several studies have clearly articulated the need for strategy formulation and implementation with greater importance attached to strategy formulation of the organization's growth in the 20th century (Cater \& Pucko, 2012) since the level of performance and competitive position of an organization increases when the management implements effective strategies (Awino, 2013; Okwachi, Gakure \& Ragui, 2013; Sage, 2015). The implementation of effective strategies has a substantial impact on the performance of organizations (Spyropoulou, Katsikeas, Skarmeas \& Morgan, 2018).

Strategy implementation is the second step in the strategic management process most scholars regard it as the most time sensitive activity in management (Barnat, 2012; Sage, 2015; Sial, Usman, Zufiqar, Satti \& Khurheed, 2013). Most organizations acknowledge it as the most challenging and involving component of strategic management, accordingly, it is recorded to be more painstaking and difficult than formulation since formulation only requires skilful leadership whereas strategy implementation requires concerted efforts and actions from all stakeholders within that organization (Sage, 2015). In addition, strategy implementation studies requires; strategic policies, strategic direction, organizational structure, corporate culture, resource capability, processes and team commitment to the strategic goals in order to reach the envisioned performance (Schaap, 2006).Therefore, amongst these steps, strategy implementation to a larger extent is a determinant of the success or failure of an organization (Barnat, 2012). Successful strategy implementation of strategies represent a fundamental fact for any organization in the event that the set goals and objectives are to be achieved. Li, Gouhui and Eppler (2008) from the analysis of a number of scholarly works and experiences of organizations posit that strategy implementation influences the performance of all organizations. It is one of the steps undertaken as a process within strategic management which, include strategy formulation, planning, control and implementation (Sial, Usman, Zufiqar, Satti, and Khursheed, 2013). From such perspective, it is therefore, worth noting that if a company is successful in executing and implementing a workable and unique strategy, then it is guaranteed significant profits including high competitive ability within the industry (Sage, 2015). Notably, the activities that define strategy formulation and strategy implementation are intertwined, inseparable and therefore should be included at the planning stage. However, most of the scholarly literature in strategic management concentrates most of their research efforts on strategy formulation and few on strategy implementation (Hrebiniak, 2013). 
Scholars of strategic management assert that between $50 \%$ and $80 \%$ of strategy implementations fail because of the managements' inability to follow up on the strategy execution processes Jonk and Ungerath, (2013) and as confirmed also by (Rajasekar, 2014). According to Sorooshian, Norzima, Yusuf and Rosnah (2010), strategy implementation is a challenge in many companies since it consumes, demands more energy and time from the management and only 10 to 30 per cent of intended strategies ultimately succeed. Strategy implementation is regarded as a crucial process within the maritime economy and requires integration and harnessing of the natural resources in waters, associated clusters in many countries for wealth creation and generation of national employment opportunities geared towards blue economic growth (AU, 2012; OECD, 2014, UNECA, 2015). According to Papadimitriou and Stavroulakis (2016) the choice of the maritime cluster and industrial cluster concepts provides analytical bases which are attractive from a strategic management point of view. These aspects create effective ways of producing positive influences as well as superior performance as observed by (Olavarrieta \& Ellinger, 2007).

In summary, strategy implementation is the summation of all activities and options necessary for the execution of strategic plans and implementation phase entailing active participation of the management team in the whole management processes in order to attain specific desired results. These include; information development, human resource management, organization structural design, resource allocation, as well as addressing areas such as reward system, accessibility to corporate staffing and leadership since such processes can also improve maritime performance (Chang, 2016).

\section{Concept of Strategy Implementation}

The concept of strategy implementation involves organizing of all the resource capabilities within an organization geared towards achieving the goals of the firm. Li and Eppler (2008) assert that the modern business environment is complex, iterative, dynamic and unpredictable. This demands that managers and employees become creative in their decision making process since they are also affected by the internal and external factors affecting businesses around the world. The first approach according to Sial, Usman, Zufiqar, Satti, and Khursheed, (2013) in the definition of strategy implementation focusing on process perspective where by the term refers to a series of sequential and carefully organized steps.

The second approach focuses on strategy implementation as a series of consecutive activities and therefore, examines activities and actions from behavioural perspective. From the behavioural perspective, implementation is defined from operational point of view as conglomeration of leadership behaviours from senior management and series of activities focusing on transforming working plan into practical concrete reality. The third aspect defines strategy implementation as a combination or hybrid of both processes and behavioural perspective. In this case, as postulated above, strategy implementation refers to step-by-step approach used in executing activities that incorporates formal decision-making approach. Therefore, the field of strategic management encompasses making plans for the organization's future and having an effective strategy formulation and direct firm's action plan. Therefore, assessing the strategy formulation process is of importance to policymakers and researchers in order to monitor and evaluate the strategy formulation and action process (Sial et al., 2013).

Statistically, studies have shown that $95 \%$ of the time is spent on strategic theories, while $5 \%$ at best on the execution and strategy implementation whereas in real world, majority of the people spent most of the time in executing and implementation, and in most cases emphasise is placed strategic planning other than strategy execution (Moore, 2012). Macleanna (2010) distinguishes formulation from implementation in the strategy by stating that strategy 
formulation is where the firm is headed to, while implementation is a blueprint of how to get to that point which proves even harder to execute (Hrebiniak, 2013). This distinction falls short of giving an accurate definition according to Zhou, Zhou, Li and Su, (2008) who describe strategy implementation as one of the most complex, dynamic, iterative and multifaceted process comprising of a sequence of decisions to be performed by both managers and employees responsible for turning strategic plans into actions.

On the other hand, strategy formulation is the work of senior management in any organization; whereas the strategy implementation is the work of the middle managers who need support from the management team in their tasks. It requires an in-depth of analysis, judgment and innovation supported by a process in which policies and strategies are executed. Supportive elements during the execution such as budgets, programs, and procedures whose aim is to make a strategy action oriented are included. In this case, the top management should give workable strategy, clear communication on implementation plans on tasks that require completion (Chelte, 2014).

Rajasekar (2014), states that strategy implementation demands for strong administrative and managerial talented skills with foresight to make clear changes and plans during the implementation process. Strategy implementation demands for various activities that include creativity in business, understanding of the arising business opportunities, the participation of the management team, resources allocation, organization composition, information systems, human resources, reward system, accessibility to leadership and staffing (Grant 2016). Strategy implementation sums up all actions and options necessary to execute and implement strategic plans entailing active participation of the management team in the whole management processes in order to attain specific desired results. These include; information development, human resource management, organization structural design, resource allocation, as well as addressing areas such as reward system accessible to corporate staffing and leadership since such processes can also improve maritime performance (Chang, 2016).

\section{Global perspective on Maritime and Industrial Clusters performance}

Clustering is one of the central concepts for analysing the competitiveness of nations, industries and firms. The clustering concept studies the clustering of maritime activities and services such as shipping, shipbuilding and port management. Maritime services are geographically concentrated in a number of maritime clusters and anchoring on ongoing internationalization and in such industries, the concentration of maritime activities in clusters is likely to increase as opined by (Langen, 2010). Industrial cluster is a set of firms and institutional bodies that are positioned in close proximity to each other and have related economic actors, with specialized services, expertise, suppliers, resources, and skills with an emphasis on increasing competitiveness and growth of a region (Porter 2011). Firms facilitate collaboration on complementary economic activities when higher education and research institutions and other public and private entities cluster together in a geographic area (Scott, 2012).

In recent times, clusters also include; the world's most leading clusters in high-technology industries ranging from textiles, wine making, and automobiles to biotechnology. Some of the key clusters are found in the Silicon Valley, Bangalore IT- high technology, Italian fashion style, and Detroit car plant in USA (Fasolo, 2010; Grill, 2014 \& Heppler, 2016). Other agglomeration economies are localized flow of knowledge within the economy as analysed from the business perspective by (Porter, 2011; Doloreux, 2017). Most countries are nowadays introducing cluster approach to strengthen their industrial competitiveness at both national and at 
regional levels in form of integration or trading blocs, which form essential aspects in the quality-based competition to the clusters being key drivers for gaining competitive advantage since clusters are said to be interconnected in that they compete, they also share information, collaborate as well as network or form synergy within the given region (Scott, 2012).

The concept of clusters go past physical proximity since it lays more emphasis on the existing links and social ties available among the actors within the cluster population and attracts key benefits derived from maritime or industrial clusters such as information spill-overs, information transfer and shared labour mobility (Huber, 2011). These localized benefits include new products through Small Medium Enterprises (SMEs) and processes which are initial development, within geographical proximity (Scott, 2012). Thus, cluster concept has gained adoption among regional and industrial development policy initiatives around the globe since clusters form strong interdependence within firms such as suppliers, knowledge agents, research and development institutions, auxiliary service providers, service companies, brokers and consultants as well as customers through linked value chain (Chul-Hwan, 2014). Minghui, (2013) observed that there is concentration of maritime firms in Europe making the region a leading force in global market share in technological innovation, and operations whereas, ChulHwan, (2014) while examining the five European maritime nations: Germany, The Netherlands, The United Kingdom, Denmark and Norway, noted that their combined industry cluster number up to 103 and employs about 4.78million people and Finland maritime accounts for 2,900 firms with total revenue of Euros 13.2billion with 43,200 employees (Karvanen et al., 2008). China employs 43million people in maritime related firms with production valued at Euros, 602 billion (Minghui, 2013; Xinhuanet, 2013) which are a clear pointer to the fact that there is an increasing global interest in maritime strategy implementation. Similarly, Singapore, Dubai and Durban for instance have also experienced successful strategy implementation in Maritime cluster firms by registering good performance in shipping; port related activities, commerce and trade, service provisions, as well as providing employment opportunities (UNCTAD, 2014).

\section{Continental perspective on maritime cluster performance}

United Nations' agency for maritime affairs International Maritime Organisation (IMO) calls for full participation in maritime affairs by all member countries. This persuades member states, agencies to pursue maritime cluster in their regions or countries (Minghui, 2013). Based on this, Africa is following suit as in pursuit of marine cluster strategy implementation (UNECA, 2004; AU \& OECD, 2014). The Study by Bueger (2013) recognizes Africa as an emerging maritime cluster continent amidst immense challenges. Africa Union has now adopted Maritime Strategy 2050, which was fronted by the Heads of States in January 2014 declaring 2015 to 2025 a decade of Maritime for African Ownership of Ships. This has, established Combined Exclusive Economic Zone - EEZ areas, and forge for (Regional Maritime Strategy RMS), and Collaboration on Maritime Trade with other Member states (AU, 2014).

Maritime development strategy can have an overall influence on how African countries participate in maritime cluster businesses as her next frontier by implementing strategies in maritime cluster for collaboration and synergy in the sector. Such positive externalities emanating from co-location have a tendency of attracting additional economic actors in a cluster, nationally, regionally and globally (Pallis, Parola \& Acciaro, 2017). Despite the potential for continued growth, there is need for considerable investments to be made in infrastructure and associated facilities as well as expanding the capabilities of personnel within the industry (Baker, 2011). 
There has been increasing willingness among actors within the continent and from economically empowered countries to develop the sector due to the vast natural resources on the African continent. For example, China Merchants Holdings (International) Co Ltd has invested heavily in Africa's infrastructure development. Such investments include; USD 10billion in Tanzania, USD 13.1billion investment in Nigeria for high speed coastal railway 1,385km of single track line (Shinn \& Eisenman, 2012. In addition to the above, a further financing a USD 1.2billion in natural gas pipeline $(532 \mathrm{~km})$ for mining coal and iron ore in Tanzania (Ng'wanakilala, 2013). African countries have also made attempts to develop the Maritime Industry and such attempts are eminent between the Nigerian and South African governments; which calls for developing of shipyards in Nigeria and operations using Nigerian labour (Oritse, 2010). Nigerian under the Nigerian Coastal and inland shipping (Cabotage Act 2003), gives exclusive rights for transportation of goods and services within Nigeria Coastland and inland waters to vessels built by Nigerians, flying Nigerian Flags, owned and crewed by Nigerian citizens (MTCN, 2007). Such endeavours ensure creation of more employment opportunities as well as improving economic growth emanating from maritime industry (Eroke, 2013).

\section{Kenya perspective on maritime cluster performance}

Government of Republic of Kenya established KMA, through the Legal Notice 76 of 2004 with the mandate of regulating, co-coordinating and overseeing maritime affairs in Kenya, through the enactment of Kenya Maritime Authority Act 2006. KMA falls under the State Department of Maritime and Shipping Affairs in The Ministry of Transport infrastructure, Housing and Urban Development (KMA, 2016). Currently, the key sectors supported by the maritime industry, include transport, tourism, fishing, mining, aquaculture, oil/ gas, and water sports. Overtime, the coastal strip plays an important role as an entry port into Eastern and Central Africa and other hinterland countries like DRC. These therefore, point to the intra firm as well as extra firm collaborations supported by innovation as stated in the investigations carried out on cross border development of maritime cluster, which identified competitiveness within similar systems presenting profitability of technology adaption for firms' better performance (Schuster \& Rueck, 2017). According to Kenya Maritime Authority (2015), there are other numbers of blue economy related resources which have not been fully exploited in both the territorial waters of the Indian ocean and within the inland water bodies; for example, aquatic resources within EEZ areas that have the potential towards contributing to blue economy, but have reported revenue losses below target of 340,866 metric tonnes worth Kshs 88 billion and only 9,134 metric tonnes worth Kshs 2.4 billion were harvested in coastal fishing production.

This calculation represents approximately $6 \%$ of the total fish production in the country. In comparison to inland lakes production, reported fishing production capacity of $80 \%$ with 130,658 tonnes and fish farming aquaculture netting in $14 \%$ with production capacity of 23,501 tonnes of the total production. This indicates that the coastal fishing industry has potential earnings of over Kshs 90 billion worth from 350,000 metric tonnes per annum if employed to its full production capacity. Furthermore, AKI (2016) maintains that Kshs 85.5 billion was lost in seven years to foreign marine insurance companies, instead of instituting cargo marine insurance through local insurance firms. The domestic contribution of the Kenyan Maritime industry has not experienced any significant improvement over a long period. For instance the industry has recorded constant total earnings of below $2 \%$ for the past two decades. In the year 2002 and 2006 the total earnings were recorded at $1.3 \%$ and 1.6\% respectively (KMA, 2010). Further, the maritime industry's contribution to employment in transport sector has been on the declining trend for the last decade. For example, the sector recorded a decline of 5.1\% between 2001 and 2006 while at the same time, its contribution to 
total earnings increased by $4.9 \%$ between 2001 and 2007. However, the support devices have had significant contribution to the economy valued at $90 \%$ of the total employment opportunities within blue economy (KMA, 2010).

The Kenyan government initiated cluster firms within the Maritime Industry with the aim of boosting productivity and competitiveness. This has been done through facilitation of the collaboration that brings together business firms, multiple government agencies, institutions and research organizations with sole purposes of enhancing performance and ultimately growth (KMA, 2010). In this case, the creation of Maritime cluster firms in Kenya was aimed at providing more productiveness in operations that includes sourcing of inputs, access to specialized information within the industry's network that is crucial in coordinating and improving access to stakeholders. Such lack of proper strategy implementation process fails to integrate policies and leads to low level performance of Maritime cluster firms in Kenya, which eventually has slowed down returns from the blue economy (KMA, 2010). The factors that contribute to lack of proper coordination between various policy areas and supportive regulatory framework greatly interfered with the level of growth within the sector, therefore, resulting into low investment opportunities, insecurity, low off-shore / onshore exploration activities as well as slow development of maritime transport related industries, all these eventually contributes to high levels of unemployment.

The Maritime business globally as well as in Kenya faces the challenge of a shortage of technical personnel to provide services in the maritime industry as observed by (Sánchez \& Wilmsmeier, 2010; Oyaro, 2013). The study shows that the concept of clustering enhances the level of competitiveness and productivity within the Maritime Industry. However, key drivers that influence transformation of business strategies into deliverable results within such Maritime Cluster firms, with mediating role of strategy implementation that ensures maximization of organizational performance have been under-utilized. In the Kenyan vision 2030 report, various domains are identified as the major platforms that significantly determine the revival and efficiency of such sectors as Marine Industry. These domains include the stability within the region in terms of security, the global economic environment as well as efficiency in the operations of State Corporations (KMA, 2010).

\section{Statement of the Problem}

Strategy implementation process presents one of the most important stages in an organization, but available evidence from majority of the scholarly articles indicate high rate existence of failure in the implementation process in most organizations. From the works of Carter and Pucko (2010), indicate that between 60 to $80 \%$ of all organization globally records good performance in strategy formulation but struggle in the strategy implementation process. On the other hand, various scholars assert that between 30 to $90 \%$ of strategy implementation fail (Raps \& Kaufmann, 2005; Rajasekar et al., 2014; Candido \& Santos, 2015). The study of strategy implementation on the performance of maritime cluster firms in Kenya has not been fully exhausted for economic growth despite its vast potential resources and several multi agencies quest working towards full realization of their goals (KMA, 2015). This therefore, results into low ratings especially towards Blue Economy's contribution towards Kenyan economic development and employment creation (KMA, 2015).

Notably, the Maritime sector contributes significantly to economic performance of many nations globally including the Kenyan economy (UNCTAD, 2014). Such contribution to the Kenyan gross domestic product (GDP) is approximately $2.03 \%$ despite Kenyan maritime trade accounting to $92 \%$ of its international trade KMA (2015), which is below the expected global benchmark of above 3.1\% (UNCTAD, 2014; World Bank, 2015). On the other hand, the value of 
the Kenyan marine transport sector is approximately Kshs 73 Billion reflecting approximately $1.5 \%$ contribution to GDP with Fisheries sector valued at approximately Kshs 20 Billion which is an approximate of $0.45 \%$ only of contribution of Kenya's GDP (KMA, 2015). Given that Maritime Industry is anticipated to contribute significantly to the Kenya's international trade and as a key driver of the overall national economy, it is important that the entire strategic management processes from strategy formulation to strategy implementation be formidable (KMA, 2015). According to Kenya State Department for Shipping and Maritime Affairs, the country is yet to reap full economic scale from the blue economy despite the country's strategic geographical location along the shores of the Indian Ocean and its entire Maritime coverage including the potential resources of hinterland locations (KMA, 2015).

There is also limited empirical evidence examining the strategy implementation and underlying factors of low performance and growth in the entire maritime sector in Kenya. Raps and Kaufmann (2005) in their study observed that very many organizations lack iterative follow up on their proposed strategy implementation processes as their studies showed that only 10 to 30 percent succeed whereas, Rajasekar et al., (2014) also affirms that 50 to 80 percent of strategy implementation are unsuccessful hence leading to organizations operating shortfall of their anticipated goals. Ansah (2017) carried out a study on the effects of strategic planning on the performance of small businesses in Ghana. The study used the resource based approach and the results showed that managerial capability and resource allocation had a significantly positive influence on strategic planning and performance of a firm.

Rajasekar (2014) carried out a study on factors affecting effective strategy implementation in electricity distribution companies in the Sultanate of Oman. The study found that the most influential factor in the strategy implementation process is the leadership.

Khayota (2014) conducted a study on the ecletic roots of strategy implementation and the results show that operational planning was one of the major reasons why the strategy implementation process in Kenya has largely been unsuccessful. Muthoka, Oloko, \& Obonyo, (2017) conducted a research on effect of Change Management Driver on Performance of Tourism State Owned Firms in Kenya and found out that the drivers of change management significantly affects the performance of state owned firms in the country.

Further, there was indication that positive organization culture, change execution as well as consistency in change vision influences performance of these state corporations in Tourism sector in Kenya (Muthoka et al., 2017). Evaluation of majority of these recent studies as indicated above show that none of them, both in local and international literature have focused on strategy implementation and its influence on the performance of maritime cluster firms in Kenya hence the gap that this study seeks to fill.

\section{Research Objectives}

The study will be guided by the following objectives:

\section{General Objective}

The general objective of the study is to establish the influence of strategy implementation on performance of Maritime Cluster firms in Kenya.

\section{Specific Objectives}

The specific objectives for this study will be:

i. To establish the influence of strategic policies on the performance of maritime cluster 
firms in Kenya

ii. To determine the effect of strategic direction on the performance of maritime cluster firms in Kenya

iii. To evaluate the effect of organization structure on the performance of maritime cluster firms in Kenya

iv. To assess the influence of resource capability on the performance of maritime Cluster firms in Kenya.

v. To determine the influence of technology innovations on the performance of maritime cluster firms in Kenya.

vi. To analyse the moderating effect of firm characteristics on the relationship between strategy implementation and the performance of maritime cluster firms in Kenya.

\section{Research Hypotheses}

Hypothesis refers to an educated guess that attempts to give explanation for a set of facts or natural phenomena based on prior knowledge (Bradford, 2015). The concept can be tested for validity scientifically (Banerjee, Chitnis, Jadhav, Bhawalkar \& Chaudhury, 2009). In this case, the study seeks to establish a causal association among objectively specified variables and the following hypotheses will be taken for the study:

Ha1 Strategic Policies have significant influence on the performance of maritime cluster firms in Kenya

Ha2 Strategic direction has significant influence on the performance of maritime cluster firms in Kenya.

Ha3 Organization structure has significant influence on the performance of maritime cluster firms in Kenya

Ha4 Resource capabilities has significant influence on the performance of maritime cluster firms in Kenya

Ha5 Technological Innovations has significant influence on the performance of maritime cluster firms in Kenya

Ha6 Firm characteristics has significant moderating effect on the relationship between strategy implementation and the performance of maritime cluster firms in Kenya

\section{Significance of the Study}

The findings of this study are important to various sectors, scholars and other researchers who are interested in the performance of maritime cluster firms. The findings will add to the body of knowledge in this field, mainly to maritime industry in Kenya and in particular, benefit the following.

\section{Top Management of Maritime firms}

The study findings are of paramount importance to management of maritime industry since they address the effects of strategy implementation on performance of maritime cluster firms. This will contribute to better understanding by the management team on the factors that facilitate strategy implementation and will assist in the designing and implementation of informed strategies that ensures enhanced and sustained performance within Kenyan Maritime Cluster firms.

\section{Kenya Maritime Authority}

The Department of Shipping and Maritime Affairs is responsible for development of the maritime industry's development in terms of regulation, coordination and oversight roles. They will also benefit since the study gives elaborate explanation on how to ensure appropriate implementation of policies that guarantees positive results. 


\section{The Government of Kenya}

Currently, the Government of Kenya is the largest shareholder in the industry and will be interested in the findings of the study. The government has a role of supporting the industry through Policies, regulation enhancement of competition, fair play, and provision of an enabling environment for all stakeholders. Appropriate implementation process would boost productivity and competitiveness within the industry.

\section{Scholars and Researchers}

The study findings are of paramount importance to researchers, as they will gain both theoretical and practical experience on strategy implementation, which has a significant effect on performance of Maritime clusters.

\section{Scope of the Study}

The scope of the study will be contextually limited to a review of aspects of strategy implementation in the maritime cluster firms in Kenya. The study will further be limited to the performance of the ten maritime cluster firms with target population of 1386 firms within maritime cluster and will be conducted during 2017/2018 academic years. The study will be conducted within 50 kilometres radius of the following regions; Mombasa City, Nairobi City, Kisumu City, and Athi River in Machakos County, within the republic of Kenya and will borrow partly from the global perspective, as it will be depicted in sections of the formulated questionnaires.

\section{Introduction}

\section{LITERATURE REVIEW}

This chapter focuses on the theoretical review, the conceptual framework and empirical review. The chapter brings in the conceptual discussion of the study variables and the critique of the existing literature. The chapter will also look at the research gaps and chapter summary.

\section{Theoretical Review}

This chapter conceptualizes the study theories: The Agency Theory, Upper Echelon Theory, Strategic fit theory, Dynamic capabilities theory, Higgins 8'S Model and Contingency theory from which the study independent variables are drawn. The balance scorecard model is adopted from Kaplan and Norton (2001) from which dependent variable of performance is derived influencing strategy implementation on maritime cluster firms in Kenya.

\section{Agency Theory}

Agency theory entails a management concept whereby an individual known as the agent performs actions on behalf of the principal for the purposes of advancing the principal's objectives. In this case, the agent is responsible for advancing the interests of the principal besides his personal interests in relation to the organizational management. There is need for balancing on the side of the agent in the process of propagating corporate objectives for the purposes of proper utilization of organization resources. Laffort and Martimost (2002) attest that the agency theory of strategic management is vital since the choice of the agent ultimately affects other parties including the principals. This makes the agent a very important element in strategy formulation and entire strategic management process. The Agency Theory focuses on the presence of a proper synergy between management and stakeholders for the reasons of attaining towards a common objective. The theory also holds an important stake in the description of managerial behavioural on leadership within the organization and how internal activities are coordinated. 
According to the study by Rugman and Verbeke (2008), the Agency Theory provides a theoretical framework for structure as well as management of contracts that forms one of the issues in strategic management. This therefore, explains the organizational behaviour that includes behaviour of principals as well as agents and how it relates to management performance. Krueger (2004) posits that the surplus of strategy implementation studies concern the practice of the agency theory at all levels of management. From his works, Krueger (2004) asserts that all the processes and objectives surrounding strategy from corporate to operational strategy must always be under the supervision of agents or managers. In this case, for success to be realized at every stage of strategy management from formulation to implementation there is need for collaboration between management as agents and the subordinates (Henry et al., 2006). This shows that agency theory plays a very important role in strategy implementation. There has to be synergy in the use of Agency Theory and for the purposes of achieving organizational goals it is paramount that the principal and agent have an understanding. This qualifies the use of Agency theory in this study especially in the overall strategic management process since it enhances competitive performance.

\section{Contingency theory of Organizational Structure}

Contingency theories emerged from the sociological functionalist theories of organizational structure (Reid \& Smith, 2000; Chenhall, 2003; Woods, 2009). These studies hypothesized that organizational structure depends on factors like the size of the organization, the technology available and the dimensions of task environment. In simple terms, contingency theory states that there is no single best way to organize a firm, lead a company, and make decisions. The best course of action is dependent on a variety of internal and external situations or factors. Contingency theory attempts to study organization structure and attempts to explain how factors like technology, culture and the external environment influence the setup and functions of organizations to improve their performance (Woods, 2009).

The main assumption of the contingency theory is that all organizations cannot operate on one single effective organizational structure. The best organizational structure is dependent on a variety of features available in the organization such as the level of technology, environmental factors, organizational size and the information system adopted (Tillema, 2015). The contingency theory is one of the most reliable frameworks that is helpful in study of the effectiveness of organizational design (Donaldson, 1995a, 2001). According to this theory, the most effective organization structure accommodates all the contingencies. The theory attempts to find a fit between how an organization fits its structure to the contingency that affect the performance of the firm (Woods, 2005).

Structural contingency theory writings fall within a functionalist tradition of social science which state that organizations become more adaptive to the ever-changing environment. The theoretical model articulated as the Structural Adaptation to Regain Fit (SARFIT) (Donaldson, 2001) includes a process which permits organizations in fit to enjoy an increase in their performance, generate surplus resources and lead expansion (Hamilton \& Shergill, 2013). These processes include expansion of geographic locations, increasing the size of the organization, encouraging increased innovation and diversification. The impact is that the firm will exhibit an increase in contingency variables, like size, resulting in an anomaly with the prevailing structure.

The misfit in existing organization structure forces firms to adopt the structural change into a fit which in turn ensures that performance improves in the long run (Ghazzawi, 2018). This SARFIT theory incorporates several aspects of the structural contingency theory, such as enacting changes in response to changing environment. Bums and Stalker (2012) also reviews 
the changes in organizational structure due to changes in technology and market attitude. Structural contingency theory therefore, contains dynamic ideas formulated in the SARFIT theory.

In structural contingency theory, an organization is affected by constant changes which lead to misfit in the structure. This misfit arises from surplus resources in the fit-based performance structure and are responsible for the expansion of the organization or its decline. The misfit increases contingency variables necessitating change in the organization structure in order to retain the fit structure. The SARFIT theory, therefore, views fit and misfit as unavoidable changes that exist in alternate forms to each other. When an organization is in fit, it will eventually expand into misfit, forcing the organization to make structural changes in order to become fit, and this process repeats itself throughout the lifetime of the organization (Tillema, 2015). The movement of the organization between fit and misfit leads to varying levels of performance, resulting in an increase of the contingencies hence structural changes. These strategic increases in contingencies lead to the expansion of organizations from small startups to larger regional and in some cases international levels with larger geographic cover and diversification (Hamilton \& Shergill, 2013). This theory will help in assessing the influence of organizational structure on performance of maritime cluster firms in Kenya.

\section{Upper Echelon Theory}

Hambrick and Mason (1984) as a framework for research on top managers developed upper echelon theory, which affirms that there are various measures of the performance of organization that are totally dependent on the characteristics of individual managers in the management hierarchy. The central idea in Hambrick and Mason (1984) paper, and the core of upper echelons theory, has two interconnected parts, namely; that executives act on the basis of their personalized interpretations of the strategic situations they face, and that these personalized constructs are a function of the executives experiences, values, and personalities (Hambrick, 2007).Consequently, the theory is built on the premise of bounded rationality, which states that informational complex and uncertain situations are not objectively knowable, but are merely interpretable (Hambrick, Frederick and Sanderson, 2015).

Upper echelons theory is based on the premise of the organizational outcome both strategies and effectiveness which reflect the values and cognitive bases of powerful actors who in this case are the strategic leaders (Carpenter, Sanders \& Geletkanycz, 2013). In particular, the theory indicates that the perception of the top managers has a high influence on the organizational strategic choices that affects organizational performance (Bell, 2007). The focus of the top management is primarily values or intellectual base and is termed as strategic leadership. This is because humans have a limited capacity to process information at any particular time, personal tendencies and dispositions end up deciding which elements to attend to in the environment. There is also an argument that personal traits of senior executives highly determine the characteristics of the surroundings that they can borrow from in order to inform the decisions that they make concerning choices, strategic or not, that might affect the organizational strategic goals performance (Hogan \& Kaiser, 2012).

A number of important features also characterize the upper echelon theory. First, as outlined by Hambrick, (2007) the underlying framework is a linear one, that is, the top management team enacts the situation, which leads to strategic choices, and those choices affect performance. Second, the study gave rise to a theoretical framework predicting that organizations will be a reflection of their top management teams and a methodology that relies on top leadership team demography as a measurement proxy for underlying individual and 
group cognitions and behaviours (Marimuthu \& Kolandaisamy, 2009). Hambrick and Mason's (1984) as well as Hambrick's (2007) arguments are a basis for this study which also holds that strategic leadership shape the strategy implementation of organizations consequently affecting performance of Maritime cluster firms. It is through strategic leadership that proper strategies and decisions are formulated that are in tandem with how strategic implementation process should be carried out. The central tenet of the upper echelon theory is that, organizations are a reflection of the skills, expertise and values of the senior leaders as they work at a strategic level (Phipps \& Burbach, 2010). The assertion is similar to one of the specific objectives that suppose that strategic leadership can influence the performance of Maritime cluster firms.

\section{Dynamic Capability Theory}

Teece, Pisano and Shuen (1997) defined the dynamic capabilities theory in their paper on dynamic capabilities and strategic management whose concept extends the RBV theory to an approach for a dynamic environment where there is an emphasis on reducing product lifecycle and an increase in competition levels and advancement in technology (Winter, 2013). The importance of dynamic capability is that it plays a role as a safeguard between organizational resources and the changes in the business environment by allowing a firm to change its resource base to achieve a better performance through exploiting competitive advantage. The dynamic capability theory refers to organizations ability to attain renewed competitive advantage by revamping organizational resources and competences to achieve analogy with the shift in business environment.

Dynamic capabilities enable organizations to realize new opportunities a dynamic business environment by converting available resources in the organization into both tangible and intangible assets and capabilities (Easterby- Smith, Lyles, \& Peteraf, 2009). The process of value-creation exploits these opportunities through effective and efficient development of new products and services. The dynamic capabilities of an organization reflect its capabilities to maximize its resource base and modify these resources for the good of the company facilitating the renewal of current processes, thus enabling the company to fit better with the environment (Zahra et al., 2006). The core dynamic capabilities are reconfiguration, leveraging, learning and knowledge creation, integration, and sensing and seizing (Barreto, 2010).

Reconfiguration consists of transforming and recombining assets and resources (Bowman \& Ambrosini, 2015). Learning is a core higher-order capability (Teece, 2007) whose subset comprises of reconfiguration, leveraging, and regenerative learning. This enables the firm to acquire and use adequate knowledge to facilitate the creation and modification of its capability and resource base (Zahra \& George, 2012). These capabilities allow for the organization to adapt and develop its other capabilities, increasing both the chance of survival and constant expansion. Renewing capabilities involves the creation of knowledge, sensing, seizing, and integration. This enables the organization to create and modify changes in its current operational capability and resource base resulting in enhanced performance. For an organization to efficiently renew its organizational capabilities in response to the everchanging external environment, it needs to have the ability to seek out new opportunities (Teece, 2007). The ability to adopt to the changing environment and the ability to generate new knowledge makes it easier for firms to meet customer demands by creating new products and product categories (Verona \& Ravasi, 2012). Dynamic capabilities are important to firms operating in the maritime industry since they facilitate change according to the up-to-date operational capabilities and resources. This provides a framework for innovation, which is necessary to increase a firm's competitiveness in the maritime industry. 


\section{Higgins 8'S Model}

Higgins (2005) developed a model by revising the original McKinsey's 7-S framework that was conceived and developed in 1980's by Peters and Waterman (1982). Higgins (2005) made improvement on the McKinsey's 7-S model by including additional S component referred to as strategic performance to come up with $8^{\prime} \mathrm{S}$ model. This was ultimately referred to as $8^{\text {th }} \mathrm{S}$ component within the model. The $8^{\text {th }}$ model resulted from the interaction of the various 7-S's components from the Mckinsey's 7-S model. The developed 8-S framework suits strategy implementation within organizations. In the Higgins 8-S model skills as one of the components of "S" is replaced by Re-source as key component. This is since the process of strategy implementation requires availability of sufficient resources to ensure success.

From Higgins perspective, 8-S's framework encourages effectiveness as well as efficiency from the side of managers in the process of undertaking their duties. These managerial duties entail those that are cross-functional as well as strategy implementation activities. Moreover, from the workings of the model, the various executives that emphasize on strategy implementation and strategy formulation focus more resources on strategy execution, therefore, raising the standard of performance within their organizations. The 8-S's framework reveals that successful strategy implementation results from the alignment of key components of the organization (8-S) and strategies for implementation within specified organization. However, it is important for the management of any organization to shape their strategies to reflect the various dynamic changes within the environment. Such processes of realigning the 8-S's components to new strategies in different work environments possess a big challenge to majority of the managers, therefore, affecting successful strategy implementation. The nature of execution applicable for each strategy ultimately affects overall performances.

There are a number of models which have been formulated to explain the strategy implementation process which is the main framework of this research. Higgins 8's model will be used to assess maritime clusters strategy implementation for the study since it particularly addresses the organizational factors which have an influence on the strategy implementation process as put forward by Higgins (2005). By Eight S's model, the management team has access to a more effectively and efficiently tool to use for strategy implementation in their organizations for better performance (Bhati, 2011) which involves aligning key organizational functions or factors with the chosen strategy for strategic performance. Higgins however, noted that implementation of these strategies may not be successful due to changes in the environment and as such, have to be re-shaped marking the beginning of challenges arising from strategy implementation.

This model has factors such as; system and processes, structure, style of leadership, shared values, staff and resources. All the factors within the 8's model can be aligned for the best possible strategic performance. Top executives within firms need to align the eight factors with the organization strategy for it to succeed. This makes up the Higgins model of strategy implementation, which the research will test in this study in reference to strategy implementation within the Maritime cluster firms' performance. Higgins 8's Model is essential to this study because the 8-S's of strategy execution is a heuristic that enables senior management to more readily, enact, monitor, and assess the cross functional execution of strategies, new or revised. Moreover, the ever changing business environment reinforces the need for strategy reformulation and/or adjustment to certain elements of the existing strategy. 
As a result, senior executives find themselves confronted with the need to integrate a number of changes in the execution of the new or revised strategy, which makes the dissemination, and integration of execution actions be especially difficult cross-functional activities.

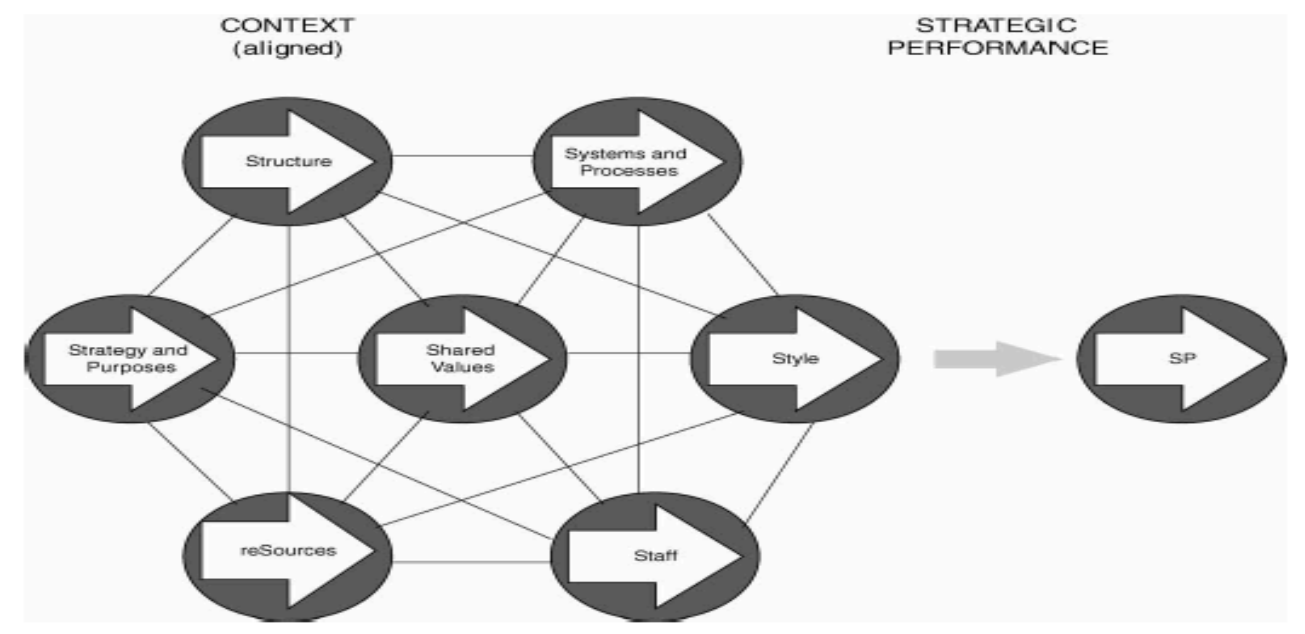

Figure 2.1: Higgins 8'S Model

\section{a. Strategy and Purposes}

The 8-S's model focuses on the fact that formulation of a strategy within an organization always aim at achieving a defined purpose. This means that in case of any change in purpose within the organization, there is need for adequate revision of strategies that would ultimately influence those specific purposes for success to be realized. The 8-S's model works in accordance to different types of strategies as identified within different organization set-ups in maritime industry. These include the business level, corporate level, functional level as well as cross-functional process.

From the corporate level strategy, the entire business operations of Maritime cluster firms and the processes of their operations are the point of focus. The business strategy entails the involvement of unique ideas in business operations that would eventually provide a competitive advantage of the individual clusters within Maritime industry. In functional strategy, the various operations from departments within the cluster firms such as production, human resource, marketing amongst others are realigned to reflect organization's business strategy. Then the process strategies entail various functional areas within the organization and their integration to processes that ultimately influences efficiency (Higgins, 2005).

\section{b. Structure}

From the perspective of the 8-S's model, maritime cluster firm's organizational structures comprises of five elements that include; job, authority behind performance, job groups, and proper coordination that ensures effective supervision as well as scope within which a manager can effectively manage to control. The functioning of all these elements determines the extent to which success is realized within these Maritime cluster firms that is in line with business strategy. For successful strategy implementation proper decisions should be made along these elements (Higgins, 2005).

\section{c. System and Processes}

The 8-S framework details systems and processes in form of formal as well as informal policies and procedures that are crucial in the process of achieving organization's set objectives. The various policies and procedures are vital elements that help in aligning organization's daily activities hence ensuring success. The procedures are applicable in the different departments 
within maritime cluster firms such as human resource department, information technology, quality control, finance and resource allocation (Higgins, 2005).

\section{d. Style}

Style is represented as leadership domain as portrayed by organization leadership in all their endeavours in ensuring harmony within processes. For instance how managers handle both employee and stakeholder relationships. The style encompasses the focus and delivery of managers in the process of delivering business objectives (Higgins, 2005).

\section{e. Staff}

The staffs represent the entire workforce population that help an organization attain to its strategic objectives. This component describes employees in details giving their background, skills and abilities including their characters. Further, the component also details issues such as training and career development, employee remuneration as well as promotion (Higgins, 2005).

\section{f. Shared values}

The component of shared values describes the organizational culture. This concept is a crucial ingredient that influences an organization towards accomplishing their strategic purposes. Organizational culture entails values that are usually shared amongst employees that help in giving them focus towards organizational goals (Higgins, 2005).It embraces corporate policies that improve an organization's competitive edge. This should not be considered as a Social responsibility, but the modern way of maximizing the use of economic resources (Harvard ISC, 2018).

\section{g. Resources}

An organization's resource base should be sufficient enough to support the processes and ensure successful strategy implementation. The processes on strategy implementation should have sufficient resources that help in facilitating successful performances. Such resources may be in form of finance, assets, manpower, management systems and technology innovations (Higgins, 2005).

\section{h. Strategic Performance}

This is seen as the derivative of all other 7-S's and results from the interaction of these components identified by McKinsey's 7-S's framework. The performance is obtained from the entire organization process and best quantified in financial terms. Therefore, balance score card provides an appropriate tool in measuring such kind of strategic performance within an organization (Higgins, 2005). The Higgins 8-S framework provides a clear overview of the components of strategy implementation and their levels of interaction that ensures successful utilization of systems thinking within Maritime cluster firm's organization processes. This model helps in realigning strategies within an organization for the purposes of conforming to different environmental changes. In this case, the model assists in the detection of different flaws within systems during strategy implementation processes, therefore, ensuring efficient outcome (Higgins, 2005).

Therefore, this model helps in underpinning the variables as applicable in this study. The study will adopt strategy and purpose on policies, structure, resources, strategy and processes (Technology and innovation) from the above stated Higgins 8's model. Further, Higgins posits that strategic performance is a derivative of (McKinsey 7-S model) seven 'S's. Strategic performance is achieved by organization as a part or the total of the profits accruing from 
organization activities that form the organizations' performance that can be measured at any level using both financial and non-financial measures (Higgins, 2005).

\section{Strategic Fit Theory}

This theory proposed by Chorn (1991) in support to the alignment theory is also known as best fit strategic management or strategic decision theory. It explains that there are no universal prescriptions of strategic implementation. Wright, Snell and Dyer (2005) argue that the application of strategic management practices depends on the institution's context, business strategy and culture. The proponents of this theory further observe that strategy implementation would be more effective only once they are rightfully integrated with specific institution and environmental understanding. Strategic fit theory elaborates the significance of making sure that strategy implementation is the rightful to the circumstances of the institution such as culture, structure, external environment and operational processes. The strategic implementation process must consider the specific requirements of both the institution and its stakeholders.

Barney and Clark (2007) attest that companies that apply strategic fit concept have better control over their resources resulting in a reduction of operational costs and better assessment of the organization's environment. Kotler and Lee (2005) conclude that contingency changes foster the emergence of new pressures which have to be adapted in the long run through execution of strategic plans. Hence for maritime sector players, it is necessary to have better control over the resources available to the company, better assessment of the environment and take advantage of new opportunities, through embracing the strategic fit concept which will enhance and guide the strategy implementation process. This theory will be utilized in the study in anchoring the strategy implementation process.

\section{Balance Scorecard Model}

Kaplan and Norton (1995; 2001) developed the balance scorecard model a key concept framework of measuring organization performance. The authors posited that the balance scorecard is a strategy-based system which focusses on results and accomplishments to make informed decisions at different levels of management in an organization. To make effective use of the balanced scorecard, it is key for organizations to focus on both performance measures and the desired result accomplishment. The balanced scorecard approach aims at providing management with a combined set of measures, which give a "comprehensive but quick" view of the business.

The scorecard serves managers by providing information necessary for managers in the form of reports which prevents sub-optimization by managers (Kaplan \& Norton, 1995). Therefore, balanced scorecard gives organizations a comprehensive review of their operations and by its use, organizations are offered clear prescription measures on how to "balance" the implications in all the functional areas, including the management practices that attempt to complement drivers of past performance such as financial measures. These also include other measures such as customer satisfaction, development of human and intellectual capital, and learning.

The balanced scorecard is quick measures of the business outlook and it is conceptualized in this study in terms of the financial perspective. This perspective addresses the effect of decision made in an organization. The balance scorecard is one of the available performance management frameworks which form basis for strategic control systems and provide a vital links between the strategies adopted by an organisation to manage strategic implementation effectively (Atkinson, 2006). 
Armesh, Salarzehi and Kord (2010) define Management Control System (MCS) as a system that organizations use to collect and make use of the information to make evaluation on the organization's performances including financial and non-financial performance, which could influence the decision behaviour of manager on implement organizations strategies.

MCS could be a system employed in a company, that collects and uses information to gauge the performance of the structure resources which will eventually influence the behaviour of the Organization to implement organizational strategies. On the other hand, on growth perspective, balanced scorecard guides in identifying, measures that link long-term growth (sales/volumes) and success, whereas on customer perspective, it is concerned with adding customer value through innovative, high quality services and the internal processes perspective (Punniyamoorthy \& Murali, 2010).

The balance scorecard model will be of great importance to the study in highlighting the dependent variable, to be contextualized using two main metrics of the balance scorecard; the financial measures and the non-financial measures of performance. The balanced scorecard measures business outlook in terms of financial impacts of priorities chosen, plans executed, decisions made and actions taken in an organization. On growth perspective, it guides in identifying, measures that link to long-term growth (sales/ volumes) and success whereas on customer perspective, it is concerned with adding customer value through innovative, high quality services and the internal processes perspective (Briel, 2014). The balance scorecard model will be of great importance to the study in highlighting the dependent variable, to be contextualized using two main metrics of the balance scorecard; the financial measures and the non-financial measures of performance for the study.

\section{Conceptual Framework}

A conceptual framework is a research tool intended to help the study to establish awareness and understanding of the situation under analysis and to communicate it (Marshal and Rossman, 2014; Shields and Rangarajan, 2013). The study will comprise of five variables, which are strategic policies, organizational structures, strategic resource capability, strategic corporate culture and system, and processes whereas the dependent variable will be performance of maritime cluster firms. Further, the measurement of performance measured by both financial and non-financial parameters as indicated in the conceptual framework shown in figure 2.2 below. 
Independent Variables

\section{Strategic Policies}

- Legal framework

- Bureaucracies

- Employees inclusivity

\section{Strategic Direction \\ - Vision \\ - Mission \\ - Objectives or Goals}

\section{Organization Structure}

- Strategic Leadership

- Internal Organization

- Organizational Coordination

\section{Strategic Resource Capability}

- Provision of raw material

- Infrastructure development

- Provision of Human resource

\section{Technology and Innovation}

- IT Systems

- Network Collaboration

- Knowledge

\section{Firm's Characteristics}

- Size

- Age (Years in Operation )

In this study, the influence of strategy implementation indicators are (independent variables) and performance on maritime cluster in Kenya (dependent variable). The moderating variable are the firm characteristics.

\section{Independent, Moderating and Dependent variables}

The above conceptual framework conceptualizes the relationship between the research variables. The independent variables for the study will be; strategic policies, organization structure, styles of leadership, resource capability, corporate culture, and the technology innovation. The dependent variable for the study will be performance of maritime cluster firms.

\section{(i) The strategy and policies}

These are aspects related to the governance mechanism that have been instituted within the organization and how they relate with the strategy implementation process. In the study, the 
strategic policies indicators will be the legal framework, bureaucracy and employee inclusivity in policy decision making.

\section{(ii) Strategic direction and performance}

The strategic direction of a firm is rooted in its strategic vision and mission statements which happens to be the first step in formulating and implementing strategies. In this study, the strategic directions that will be discussed are vision, mission and objectives or goal on which the firms in the maritime cluster depend on in achieving their performance.

\section{(iii) The organization structure and strategy implementation}

This determines how tasks and roles are shared within the organization, enabling the firm to meet organization goals. In the current study, organization structure will be assessed by use of the internal organization, the organization coordination and leadership.

\section{(iv) The resource capability and strategy implementation}

The resource capability not only drives the strategy implementation within a firm but it also enhances the competitiveness of the firm owing to the unique resource holdings. The resource capability of the firm will be measured by the availability and provision of raw materials, infrastructure development and provision of human resources.

\section{(v) Technological innovation and strategy implementation}

Information technology has become a key driver in business functions in almost every organization which brings great expectations in terms of investment on cost reeducation, enhancement of productivity, implementation of new business strategies, bench marking of business performance and gaining of competitive advantage, Organizations apply technology on a daily basis in the process of conducting their duties as well as responsibilities and in this case, technology is embedded in almost all activities and practices within maritime cluster firms for all their processes and communications internally and externally which include; organization structure, systems processes, leadership, marketing of goods and services, which makes technology crucial ingredient in the determination of successes and competitiveness for the organization.

Therefore, adopting modern technology within the firm, fosters the creativity, innovativeness, networks and collaboration activities within maritime cluster firms that leads to the performance and in the current study, system and processes will be accessed by following indicators; IT systems, network collaboration and knowledge.

\section{(vi) Organization performance}

Performance within maritime cluster firms measures their ability to attain to set objectives or aims. For this study, performance will be evaluated based on two dimensions of the Balance Scorecard by Kaplan and Norton (2001); which will be the financial measures and nonfinancial measures based on firm's size and age (years of operation). Firm's competition performance measure will include sales volume growth and market share; financial measure will include ROA, ROE and sales volumes (growth) while non-financial measures will be new product adoption/value addition.

\section{(vii) Size and Age of the Organization}

In this study the moderating factor will be the firm operational age and the size. The size and age of the organization will measure the firms' capacity and level of growth based on number of employees and maturity level within the maritime sector in Kenya. 


\section{Empirical review}

Pearlson, Saunders and Galletta (2016) acknowledge that there has been growing realization among policymakers about the necessity of developing sound strategies which ensure that the structure of the organization; systems, the leadership; organization culture and human resource policies are aligned to the strategy for successful strategy implementation. Further empirical evidence has suggested that there are minimal challenges that occur in the strategy formulation and evidence has supported the notion that most problems occur during execution of the strategy (Dannenmaier \& Dannenmaier, 2007). Despite organizations investing heavily in the strategy development through utilization of proposed models such as the Porter's Five Forces, Puempin's Strategic success, the position is that, there have been numerous challenges facing the strategy implementation as the case in the crude oil rich industry production of Niger Delta in Nigeria due to hostile environment (Courson, 2009). However, there are other internal aspects such as lack of organization structure, resource allocation, information, decision process and management of human resources aspects, which can curtail the success of strategy execution in an organization (Lewis \& Sheppard, 2006).

Usman, Kamau and Mireri (2014) conducted a study on the influence that the implementation phase has on the performance of a project in the building industry in Abuja, Nigeria. The research adopted descriptive and explanatory approaches in the study. The results of the study indicated that poor planning, budgetary allocations and poor management led to poor performance of the projects. The study focussed on the building industry whereas the current study will explore the maritime sector in Kenya. Furthermore, the study by Usman, Kamau and Mireri (2014) assessed project performance whereas the current study is examining influence of performance across the maritime sector.

Isaac, Masoud, Samad, and Abdullah (2016) studied the mediating effect of strategic implementation between strategy formulation and organizational performance within government institutions in Yemen. Structured questionnaires provided the data that was used in the research. The data was analysed using structural equation modelling through AMOS. Strategy implementation was conceptualized using; strategy, structure and human resources. The results indicated that strategy implementation significantly influenced the level of performance and a moderate mediating role on strategy formulation and the organization performance. The study concentrated on government institutions whereas the current study will focus on both government and private firms in the Maritime sector in Kenya.

Alam and Islam, (2017) examined Impact of Blue Ocean Strategy on Organizational Performance: A literature review towards implementation logic. The study was premised on the notion that blue ocean strategy offers a conducive framework for creating an innovative, value-oriented and competitive market. The results of the study indicated that Blue ocean strategy positively influenced performance. It is, however, necessary for firms to examine their size, industry conditions and adaptability for optimal performance. The study did not examine the aspects of blue ocean strategy implementation and how they individually affect the organization performance.

Ansah (2017) conducted a study on the relationship between strategic planning and performance of micro and small family businesses in Ghana. The study targeted CEO's of the small firms using close-ended questionnaires. The study concluded that strategic planning had an influence on the firm performance with managerial capabilities and resource allocation having a higher moderating influence. The above study examined strategic planning aspect whereas the current research work will focus on the strategy implementation phase and its influence on the performance of maritime cluster firms in Kenya. 
Alharthy, Rashid, Pagliari, and Khan, (2017) conducted a study on the factors that influence strategic implementation and the effects that they have on performance. The study employed a systematic review of literature with the result being analysed using content analysis. The findings of the study indicated that the coordination between the staff members, proactive approach within the organization, maturity of policies and business partnerships were key aspects of strategy implementation that enhanced the performance of firms. The study relied on secondary data whereas the current research will utilize both primary and secondary data. Abass, Munga, and Were, (2017) examined the relationship between strategy implementation and performance in county governments of Kenya: A case study of Wajir County government. The study utilized Mckinsey7S framework, Higgins 8S framework and Resource Based View theory to form the conceptual framework of the study due to their extensive coverage of the research premises. The study utilized structured questionnaires for data collection with the data being analysed using descriptive, inferential and content analyses. The results indicated that organization culture; leadership style and organization structure had statistically significant influence on the performance while resource availability had statistically insignificant influence. The study however did not take into consideration system processes and strategic policies, which this study will examine.

Masinde (2017) examined the effect of strategic management drivers on operational performance of container terminal: a case study of Kenya ports authority. The study adopted a descriptive research design with stratified sampling utilized in selecting personnel working at KPA. The collected data was analysed using descriptive statistics. The results of the study indicated that collaboration and strategic leadership had a positive influence on operational performance whereas strategic information technology had an insignificant effect on operational performance. The study examined KPA only whereas the current research will focus on the entire maritime sector in Kenya.

Muthoka, Oloko, and Obonyo, (2017) examined the effect of change management driver on performance of Tourism in state owned firms in Kenya whose findings indicated that consistence in change vision coupled with an elaborate organization culture and structure were positively related to performance. Despite congruence in the indicators (culture and structure) utilized in the above researchers; the study did not consider aspects such as resource capability and system processes which the current study will evaluate on how they influence performance. Awino, Njeru, and Adwet, (2017) conducted a study on Strategy Implementation: Mckinsey's 7s Framework Configuration and Performance of Large Supermarkets in Nairobi, Kenya. The study employed a descriptive research design with Pearson correlation and factor analysis utilized in the data analysis. The results of the study indicated that there was a correlation between Mckinsey's $7 \mathrm{~s}$ indicators and firm performance. Overall the research indicated that the Mckinsey's 7s framework is an adequate tool for fostering the performance of firms. The current study will utilized the Higgin's 8s model hence its will be of importance to examine if there is any variations between the two fundamental frameworks in strategy implementation.

Omondi (2016) examined the Effects of Performance Contracting Implementation on Service Delivery at Kenya Ports Authority whose study findings indicated that standard and performance targets had the highest influence on service delivery whereas further findings showed a positive influence between incentive systems, performance evaluation (Key performance Indicators-KPIs) and the service delivery within the ports authority focusing on service delivery. All the above studies show that limited studies have been done on influence of strategy implementation on performance of maritime cluster firms whereas the current 
research will explore firms' performance from both a financial and a non-financial perspective whose gap the study seeks to fill focusing on the entire maritime cluster firms in Kenya.

\section{Firms Performance of Maritime Cluster}

Within the maritime sector, Europe is a dominion for maritime since its maritime sectors take the lead as far as market share, technological innovation, and global operations are concerned (Wijholst, 2006). Measures such as the net sales, export intensity and the Return on Assets/Equity/ investment (ROA/ROE) have been widely used to measure performance (Zeng et al., 2009). This include customer perspectives, internal business perspectives, financial perspectives, and "learning and growth" perspective through balance score card (BSC) by Kaplan and Norton (2001). This is helpful in translating the strategy of the organization into operational performance indicators and targetted objectives. Further researchers have made use of market share and growth globally as a measure of firm performance (Hult et al., 2008). Other measures used in research include satisfaction with the profits from export activities, attainment of strategic goals and the success of the firm leadership in international ventures (Tseng et al., 2007).

In reference to the Resource Based View theory, the continous performance and competitiveness of a firm is due to rationality on the management, better resource accumulation and deployment as well as industry factors (Belgraver \& Verwaal, 2017). The RBV highlights the effects of heterogeneity in a firm as opposed to the effects of the external environment on the performance of a firm in both local and international markets as observed by (Tseng et al., 2007). Literature on maritime business research has indicated that researchers have concentrated on attaining knowledge on the determinants of firm performance Hult et al., (2008) while some of the researchers have indicated that it's challenging to come up with indicators that are adequate in measuring the performance of firms within a global dimension (Zeng et al., 2009; Lu \& Beamish, 2006).

Other researchers are of the view that it is necessary to measure performance using multiple indicators so as to portray the true picture of the firm performance globally (Sousa, 2004). Appropriate operationalization of performance is key when assessing the determinants of success of maritime firms, Hult et al.,(2008) whereas in some context,market share has been used widely as an indicator of the firm competitiveness and performance within a global dimension. According to the study by Henrik Sornn- Friese Rene, Taudam, Poulsen \& Martin Jes Iversen, (2012) indicated that the performance of the maritime cluster firms are measured in value added. In addition, the institution setting plays a major role in fostering competitiveness within firms for example, the government regulatory policy, interest organizations and availability of education, and research institutions. The role of the government should be geared towards developing supportive legislative frameworks since successful clusters will reinforce and upgrade themselves.

Research has further indicated that products and services provided by the maritime clusters are crucial performance indicators. However, globalization of maritime firm activities is key in increasing their knowledge base and professionalization of activities. Norwegian equipment suppliers focus on special technologies and provide products and services for demanding conditions in both offshore and the fishing sector (Monteiro, de Noronha \& Neto, 2013). ChulHwan, (2014) states that five major European maritime clusters counties; Germany, The Netherland, The United Kingdom, Denmark and Norway whose combined clusters number up to 103 and employs 4.78million people with annual revenue of Euros, 30billion. Kenya employs 11,366 people KMA (2015) whereas Finland maritime accounts for 2,900 firms with total revenue of Euros, 13.2billion and employs 43,200 people (Karvonen et al., 2008). On the 
other hand, China's has 43million people employed in the maritime cluster firms with production valued at Euros, 602billion according to Minghui and Xinhuanet (2013), which proves that there is an increasing global interest in maritime strategy implementation.Since establishment of KNSL in 1988, it depends on other international shipping lines (MSC) by hiring cargo (slots) container space for its commercial activities as compared to Ethiopia's (land locked country) with its own 14 commercial vessels and oil tankers nesting annual revenue of USD 40 million (KMA, 2015).

Furthermore, AKI (2016) maintains that Kshs 85 billion was lost for the last seven years to foreign insurance companies which could contribute to Kenya's economic growth at Ksh 2.2 billion per annum. The potential of the Port services in the provision of employment opportunities is a crucial aspect that requires close attention by the government. For instance, the traffic at the Port of Mombasa improved by $25 \%$ in the year 2011, this was a representation of the throughput value due to increased containerized traffic. However, the output value decreased by $5 \%$ within the same year. On the other hand, despite increased import rate, the export rate recorded a decline at a rate of $13 \%$. These figures reveal an average performance of the port which still requires significant improvement to achieve the Kenyan vision 2030 goal (KMA, 2015).

\section{Strategic policies and Performance}

The role of governance or policies in the performance of maritime clusters is evident in the maritime industry. Maritime or ocean economy is subject to a multiplayer regulatory framework under United Nations Convention of the Law of the Sea (UNCLOS 1973-1982) and other national, regional and multilateral as well as governance regimes. The foregoing is evident at national and/or a regional cluster organization according to UNCTAD (2014), such as maritime cluster representing European maritime star-regions. This is clear evidence that most European countries with sea-related sectors are supported by their governments and they collaborate through maritime clusters whose approach fall into two main patterns of clustering; government-induced setup (top-down) or clustering induced by the leading organizations within a sector- bottom-up (UNCTAD, 2014). Thus, cluster policies have become a challenging aspect to measure performance mostly, due to bureaucracy and the challenges in estimating the impact of cluster policies and programs due to the fact that only a few maritime cluster organizations measure their activities on the performance since most cluster organizations are evaluated by their member based on membership contributions (Raps \& Kauffman, 2005).

Rajasekar (2014) observed that there are some challenges facing effective strategic implementation such as, lack of reference, which can support firms' performance as a whole. It gives a hint on how far the study on the challenges facing effective strategy implementation has gone and refers to the ever-changing context of the business environment and offers much insight. While Njøs and Jakobsen acknowledge that there is much known on strategic planning just as much problems encountered during implementation, they paint the gap on knowing what to do and actually doing it during implementation. Thus, point to the need for a "systematic knowledge" on how to merge a well-thought strategy into the day-to-day operation of a business therefore, despite this articulate attempt, the need to capture specific industry uniqueness opens wider gap for relating some of the suggested solutions to the specific industries and making the "systematic knowledge" specific (Njøs \& Jakobsen, 2016)

The previous study review in Kenya noted that top managers of state corporations have been reluctant in involving junior employees in strategic policy formulation. This limits the success 
of strategy implementation and ultimately the performance of the firms (Kobia, 2013; Ndubai, 2016). The study by Mankins and Steele, (2005) also pointed out that in various organizations have strategic potential values of $63 \%$ while the study by Candido and Santos (2015) indicates that 50 to $90 \%$ of business strategies. According to the study by Crittenden and Crittenden (2008), there is a gap between formulation and implementation process since the lack knowledge of the company's strategy by the employees makes them unable to comprehend their roles in the strategy implementation process leading to poor financial performance. However, with proper orientation of strategies formulated to all employees, great success of strategy implementation within the organization is possible. This can be achieved through better governance structures that foster inclusivity of employees within a firm. The study however focuses on interlink between formulation and the implementation process; whereas the current study seeks to expound on causal link between strategy implementation and firm performance. Nonetheless, the study by Njøs \& Jakobsen (2016) establishes that consensus among workers, communication, adapting to organizational culture, motivation and support, making unemotional decisions during conflict resolution, involving employees at the strategy planning phase, prudent resource allocation, making employees understand the strategy, and building teams for strategy implementation can lead to better performance (Montano-Hirose, 2009). On a cross-case analysis, communication and building consensus come out primary since elements like enthusiasm are a cause of clear communication, which highlights why the employees should follow a goal. Shipping companies are innovative as they engage with customers, suppliers, or other stakeholders in a process of interactive planning Doloreux and Meloncon (2008), concentration strategy is implemented in shipping industry with an aim of achieving strategic goals and enhancing competitiveness in the industry to improve performance (Panayides \& Wiedmer, 2011).

Legal frameworks are important within the operations of firms that seek to implement a given strategy or improve performance according to (Grant, 2016). Thus, those that govern the operations of the clusters embedded within other laws and regulations governing the organization and economic activities and therefore, in order to ensure that a legal architecture are effective, it should set out rules that govern state institutions and how they should be structured, manage their fiscal operations, licenses and other environmental activities. Additionally, the legal framework in place should focus on the relationships between the maritime clusters and neighbouring communities. Other legal responsibilities are the ethical responsibility of public officials, disclosure and sharing of information, accountability measures and the revenue sharing formula; therefore, during initial set up in foreign states, companies should ensure they are well acquainted with the laws and regulatory provisions of the host country (Hommel \& Thomas, 2014).

Legislation is the legally binding set of rules that govern the vision established in a strategic policy and are supposed to improve the performance of firms and in most cases; well-endowed countries have set up laws that govern the exploration or mining of natural resources among others (Ostrom, 2015). Other general's laws form a major component of the industry regulation such as the environment regulation, tax laws, labour laws and the land management laws therefore, in order to foster, the Maritime sector within Kenya the government should focus on unifying the relevant policies within the sector. These unifying areas will support knowledge sharing, attaining best standards in the market and better innovation, which will strengthen the maritime sector in entire the country Eisma-Osorio et al., (2009) which reveals that common solutions for the maritime cluster can be the unifying policy aspect include innovation, accessibility, safety, trade, human capital, the environment, security and stability (Kumar, 2017). 


\section{Strategic direction and performance}

The firm's strategic direction is embedded in its strategic vision and mission statements. Therefore strategic vision and mission is starting point in formulating and implementing the firm's strategies. The firm's strategic vision provides the logical reason for future plans and directions of the organization. It aims the organization in a particular direction while providing a long term strategic direction to follow in line with the aspirations of shareholders (Madu, 2013).

According to Benson (cited in the Economist, 2009), the pre-requisite of strategic direction is a "mental image" of the possible and desirable state of the organization.

"This image, which we call a vision, may be as vague as a dream or as precise as a goal or a mission statement". "In order to realize strategic intent or direction, some level of activities and behaviour in an organization are required" (Hamel \& Prahalad, 1989). In respect to this, the organization need to redirect all her energies to discover ways that confers success, mobilize, marshal and allocate requisite resources, communicate effectively to all staff, motivate employees and clarify issues on a timely basis when there is change or need to change.

"Strategic intent ought to additionally produce an inside firm wide tension, inspiring and compelling all employees to be dedicated to the specified future direction" (Hamel \& Prahalad, 1989). Before a method is enforced, it has to be formulated first. A lot of information and participation of all stakeholders is required during the strategy formulation stage. The firm's leadership work hard to create the awareness among all employees and the stakeholders the direction the organization is headed and how the stakeholders will benefit from implementation of a new strategy. These efforts are meant to create a shared vision among all stake holders about the benefits of the new strategy. This step is very crucial before and during the strategy implementation process. The strategic direction in this study was considered as an independent variable that is often related to the first stage in the strategic management process which involves strategy formulation. It is during the formation stage that the organization usually sets its goals and objectives which are well aligned to their vision and mission statements. This process also gives the organization a general focus, an identity and the direction needed to be followed to achieve her goals. A number of scholars in management has attempted to link strategic direction generally mentioned strategic intent to structure performance.

These studies have yielded mixed results. Outcomes of some of these studies are discussed in the foregoing. Lumpkin and Dess, (1996) observed that the relationship between strategic orientation and organizational performance is influenced by many third-party variables, and the different effects of third variables may lead to different performance levels. The researcher recommended that studies on the complex relationship between strategic direction and other predictor variables should be conducted in specific context. As Liu and Fu (2011) noted, several studies on strategic direction has been conducted in large established companies (Jantunen et al., 2005), in the context of SMEs (Wiklund \& Shephend, 2005), in industry cluster context (Dai \& Li, 2006), in international background (Martin \& Lumpkin, 2003) but their findings on the relationship with performance are not consistent

O'regan and Ghobadian (2006) did a study based on the importance of capabilities for strategic direction and performance management decision. This study found out that generic organizational capabilities have a positive impact on strategy deployment and on the 
achievement of overall performance. This study concluded that generic capability is one of the main drivers of performance and firms seeking high overall performance would well be advised to ensure that they actively consider their generic capabilities because the basis of their strategic direction. Odita and Bello (2015) conducted a study on strategic intent and organizational performance in the banking sector in Nigeria. This study found out that strategic direction is positively and significantly related to organizational performance. The study also revealed the existence of a positive relationship between various dimensions of strategic direction such as goals and objectives, mission and vision with the organization's performance. Specifically, the study found that the objectives component of the strategic direction accounted for $58 \%$ variance in organizational performance while mission and vision accounted for 47 and 19\% variations in organization performance respectively. The study concluded that strategic direction has a significant positive relationship with performance in the banking industry.

Kitonga, Bichanga and Muema (2016) studied the role of determining strategic direction on not-for-profit organizational performance in Kenya and found out that strategic direction has a significant positive influence on performance in these organizations. Strategic direction is the cornerstone upon which strategies are crafted, developed and eventually implemented. Therefore, it is paramount that strategic direction needs to be very clear and understandable to all stakeholders in an organization. Leaders in SME firms need to develop their directions with vision and mission in mind. Once developed then crystallize it and cascade it downward to all employees who need to know the direction their organization is taking. Finally, the strategic direction should be the impetus upon which strategic actions and activities are designed and operationalized.

\section{Organization Structure and Performance}

Empirical evidence has shown that finding a fit between the organization strategy and the structured organization fosters the performance of the firm as the organization structure Biesta 2010) supports the necessary systems and processes required to support successful strategy implementation (Zheng, Yang \& McLean, 2010). However, some international studies show significant relationship between organization structure and the successful implementation of the strategy. These studies indicate that firms with a fit between strategy and structure can only manage a slightly higher performance than firms that do not have a fit due to external challenges (Hou, Priem \& Goranova, 2017).

Organizational structure presents interaction within the organization, communication flow, and defines power relationships reflecting on the value based choice made by a company and the coordination of tasks (Munyoroku, 2012). Observations by Ashkenas et al., (2015) states that organizational structure 8refers to the way an organization arranges people and jobs be performed and its goals met. Organizational structures are necessary for employees to act readily on the knowledge developed to construct and implement strategy. The structures also provide a visual explanation of the decision-making process and resource allocation (Rajasekar, 2014). The study by Bhimani and Langfield, (2007) found the process of strategy implementation to be structural and formal in their study to investigate how the organizational structure influences strategy implementation.

Leadership presents one of the most vital elements in strategy implementation (Teece, 2014). This is since all the responsibilities that surrounds strategy implementation are steered by leadership within an organization. However, leaders struggle with the challenge of determining the most effective organizational structure and the most appropriate time to instigate change in the organizational culture (Chaudhry, Yuan \& Cooke, 2016). The study by Qi, (2005) puts 
forward seven factors for successful strategy implementation; namely adequate feedback systems, sufficient resources, good leadership and direction skills, motivation for all involved staff, communication and coordination, and an appropriate company structure. Appropriate company culture has a significant influence on whether or not a certain strategy execution succeeds or not (Chang \& Tharenou, 2004). The study by Ling, Siek, Lubatkin and Veiga, (2008) on the styles of leadership influence on performance, the results shows a significant relationship between transformational top management and the performance in business organizations. Their findings reflect the presentation in Upper Echelons theory's which shows that manager's characteristics influences the extent of organizational performance.

The study by Forman and Argenti (2005) found out that the internal communication policy of a company significantly contributes to the successful implementation of the strategy. Cluster organizations are formed with the aim of installing a structure which provides clear solutions for cluster-issues (Steets et al., 2010). The main reason for the establishment of maritime cluster organizations is to foster competitiveness and create awareness on the maritime sector as well as enhance collaboration within clusters (Mills, Reynolds \& Reamer, 2008). In their study Caffrey and McDonagh (2017) stated that the main challenge to implementers of strategies is to perform certain tasks within the organization that seek to align the internal operations of the organization with the strategy and ensure there is support towards successful implementation of the intended strategy. Furthermore strategy seek supportive matchers with organization aspects such as skills and capabilities, the incentive systems, the organization structure, information and control systems, budget programs as well as the shared values and cultural norms (Panagiotakopoulos, 2016).

Koech and Namsonge (2012) examined the effects of leadership styles on organizational performance of state owned corporations in Kenya. The study revealed that there is a high correlation between transformational leadership and performance while there was low but significant correlation between transactional leadership style and performance. However, there was no correlation at all between passive avoidant leadership and performance. Research by Okwachi et al., (2013) on Kenyan SMEs and found out that leadership practice has a direct relationship with strategy implementation. Therefore, the study conclusions reflected the fact that managerial practices greatly influence the outcome of the strategic implementation process in Kenya. Organizational structure institutionalizes what kind of people interacts with each other, how communication flows, and what power relationships are defined according to Brown and Duguid (2017) and it is also defines how job duties will be formally executed, grouped and coordinated. Furthermore, it details how responsibilities and power will be allocated and how work procedures will be carried out among personnel. To some level each situation during the strategy implementation is unique hence may require to be aligned to specific organizational environment at hand (Simons, 2013). For strategy implementation to be successful, an effective internal organization structure and competent personnel should be assigned throughout the process, which are; developing an effective organization structure, developing skills and competencies among employees and selecting appropriate personnel to fill key positions for effective strategy implement process (Grant, 2016).

\section{Resource Capability and Performance}

The study by Tan and Thai (2014)) state that the competitiveness of any organization is widely related to the ability of the organization to exercise and maintain control over its resources and more so to organize the resources in a unique and easy to imitate method. Maritime clusters can foster their competitive advantage based on effective strategy implementation as well as 
efficient resource utilization. A firm's resource consists of tangible, financial resources, human resources, capital resources as observed by (Progoulaki \& Theotokasand, 2010). This therefore, validates the fact that effective strategy implementation is achievable when the organization resources are aligned to the strategic priorities and the set achievements on key performance measures identified through diversification processes based on resources and competences as an effective way of producing positive influences and superior performance (Olavarrieta \& Ellinger, 2007). Resources such as financial, personnel and time have to be included in the company's budget from the beginning before deployment (Allio, 2005).

These are to be agreed upon at prior stage of discussion to be framed in implementation planning process according to (Mankins \& Steele, 2005). Resource planning provides an opportunity to develop efficient planning tools for material-based, service-only, and serviceplus-material strategic plans (Johnson, 2001). The study on Kenya's maritime sector policy pointed to an infrastructural weakness in the local and neighbouring clusters. For instance; decongested ports, bureaucracy, poor railway system and poor road network in Kenya by then, led to poor performance. In addition, other weaknesses were identified as poorly integrated maritime firms, poor data, information base and inadequate human resources due to lack of international certification standards by Kenyan institutions in accordance with IMO, which pointed to a serious decline of infrastructural resources, a condition that influences the performance of the maritime clusters (KIPPRA, 2009). The study by Zaribaf and Hamid (2009) suggests that strategic planning and human resource management are indistinguishable in most successful organizations since the two works as a team. Policies and strategies relating to individual management are implemented through the management function of human resource management which appreciates human resource factors as the Key elements for the success of businesses in strategy implementation processes (Omolo et al., 2012). Human resource practitioners are better placed to pioneer the realization of such factors in strategy implementation, Ali (2013) and further, human resource factors are contained in the human resource function that have eight menus of HRM practices from which companies can choose the ones that are most viable for implementing their strategy. The above analysis reveals that recruitment process, administrative function are not just human functions, but are also a strategic process aimed at contributing to the organizational objectives as poised by (Kenya Public Service Commission,2015). This underlines the significance of recruitment to strategy implementation process of having a well-planned human resource, coordinated and knowledgeable to execute strategies (Lavigna \& Hays, 2005).

The study by Chimhanzi and Morgan's (2005) concluded that firms that are able to align their marketing and human resources are more likely to see success in the strategy implementation process. The findings further indicated that it is necessary for marketing and human resource managers to form a relationship that fosters effective reward systems, and written communication. In order to foster strategy implementation, some key issue to be addressed include inadequate resources, ill-defined plans, lack of accountability, corporate culture barriers and ineffective communication according to the study by (Brannen, 2005).

\section{Technological Innovations and Performance}

The success of the cluster approach within the maritime value chain was induced by clustering on European level emerging trend demonstrated by successful European waterborne technology platform which has brought together European Maritime Cluster collaboration for the formation of vision 2020 document on which strategic research agenda has been based (Wijinolst, 2006). In the contemporary business world, the use of information technology (IT) enhances the competitiveness of a firm. More than half of the information technology budget is spent on information technology infrastructure, not just to support information sharing but 
also to boost flexibility within the firm and response to changes in the business strategy. Hence, there is need for substantial investment on IT infrastructure within the organizations in order to support strategy implementation. It is widely accepted that IT has significant effect on the productivity of any company Chen Tsou (2007http://www.informationr.net/ir/123/paper314.html - a95) therefore; these effects are fully realized if and when, IT is properly used, which makes the introduction of technology into an organization heralds a number of challenges to the management especially during project execution period. On the other hand, a study by Chung, Hsu, Tsai, Huang and Tsai (2012) highlighted the importance of information technology in implementing Customer Relationship Management (CRM) strategy and concluded that the relationship between information technology and implementation of CRM strategy is positive, therefore, organizations should strive to properly align the business strategy and the information technology systems.

Therefore, most managers have become well equipped to guide the technological changes into routine, hence fostering the implementation processes to better business performance (Burke, 2017). Brown and Duguid (2017) are of the view that there are four elements in the adoption of information technology; IT infrastructure, the strategic alignment, the individual learning of IT and the organization culture. The information technology infrastructure is of great importance in fostering responses in business strategy within organizations (Salleh, Akma, Rohde \& Green, 2017). Strategic alignment literature shows that the influence of information technology on the organization performance depends largely on how the IT strategy and the business strategy are well aligned (Brown \& Duguid, 2017). It follows therefore that organizations can foster the information technology-business strategy alignment by ensuring there is a balance between the external and internal factors of business strategy and the information technology aspects.

The organization structure literature indicates that there are formal lines of communication within firms that help in control and coordination of work activities. While the IT is being adopted, the organization culture can be restructured to improve performance and be in tandem with the adopted information technology (Dewett \& Jones, 2004). Lewis, BrandonJones, Slack and Howard (2010) argue that, an important aspect in the role of technology advancements in strategy implementation is the collaboration in the information system. This calls for a similar system to be utilized in upward and downward information sharing. In addition to the foregoing observations, management information system collects and organizes company data efficiently improving the output of the managers. Thus, there is need for further alignment to be achieved between the information systems and the organization structure and the available resources to avoid constraining the strategy implementation process (Lewis et al., 2010). Dale, Wiele and Iwaarden (2007) revealed that the increasing need for improvement of quality has led to the development of quality systems which handle all aspects that have an influence on quality. These start from product design and culminating in service to the user and it is noted that changes in the complexity of products and the responsibility for quality standards has shifted from operators to the quality control departments. Customers in recent years are more focused on high quality products and services thus, there is need for the management to be well aware of the parameters that gauge the product quality and its concepts (Dale, Van Der Wiele \& Van Iwaarden, 2007).

Monteiro, de Noronha and Neto, (2013), state that using ecosystems to coordinate maritime stakeholders' efforts towards meeting specific challenges is becoming more prevalent in the twenty-first century. Moreover, to operate sustainably, maritime firms see the need to 
understand and maximize the maritime ecosystem. It is necessary to identify the players, their business models and the factors that unite all the players (Monteiro et al., 2013).

\section{Firm Characteristics and performance}

In this study the moderating factors were identified as the number of years of operation of the firm and the size. These two factors have significant moderating influence on the overall performance of the organization (Kihara, 2017). Generally, the size of the organization usually determines the nature of business and quantity of processes it can accommodate at any given time. However, the previous studies done on the relationship between size and performance has yielded mixed results. For instance, the study done by Capon, Farley and Hoenig, (1990) failed to identify any significant relationship between the number of employees (size) and organization performance.

Other studies by Zumitzavan and Udchachone (2014) revealed that organizations with few employees could otherwise perform better than that with many employees. However, other studies such as Lee \& Giorgis, (2004) a.nd Ural \& Acaravci, (2006) reveal a positive correlation between the size of an organization and level of profitability. The size of an organization contributes towards helping in the achievement of economies of scale. This makes it possible for such an organization to lower their market prices on certain products but still break even and also capability of large resource base. At the same time, the duration of operation of a firm also determines the nature of an organization's dynamics which otherwise affects a firm's level of growth (Yasuda, 2005). In this case, an organization's stability within the industry of operation may be determined by the number of years it has been in operation. This is since experience improves their innovative abilities and therefore, helps such firms to develop structures that are workable within their areas of operation (Hui et al., 2013). Therefore, these moderating factors have the ability of influencing the variables identified in this study.

\section{Critique of Existing Literature}

The studies show that implementation of a strategy is one of the most tasking activities in an as proved in Dandira (2011), among other cited authors in the earlier literature. In their article on strategy implementation, Candido and Santos, (2008) note that companies have recognized the challenges related to strategy implementation for a long time. Despite this criticism, strategic management is a widely practiced within the corporate world and it has served many companies around the world. On the other hand, recent times have seen progress in the field of strategic management, influence of strategy implementation on firm performance in maritime sector, as it remains adequately studied (Barney, 2001).

More attention towards clustering is directed to the work of Porter $(1990,1998)$ as cited by Zhang and Lam (2017) by policy makers and researchers who argue that clustering is a new frontier for national economic thinking which gives the nation's insight on the advantages of maintaining assets that offer competitive edge to firms. This is also supported by Bergman and Feser (1999) who recognize that the majority of clustering adopted Porter's work as the starting point including Porter's notion of diamond model for national competitiveness as a key tool for policy makers even though not all clusters can utilize this model for all clusters. This is evident in a study on clustering in Europe which indicated that not all cluster programs were initiated as a result of in-depth national analysis, which is similar to Porter's cluster mapping processes (Lagendijk \& Charles, 1999). In contrast with Porter's study, Enright (2010) indicates that nowadays only a few clustering processes adopt Porter's approach due to changes in the business environment and location. Therefore, Porter's work should only be utilized as a catalyst of initiation and development of clusters and not as an adopted rigid manual or reference for development point towards clustering (Enright, 2010). Wessner and 
Wolff (2012) posit that clustering as a new front in strategic management aims at attaining competitive advantage amongst firms and the same view is also shared by Mokhele (2015). The study by Kibicho (2015) was on the factors that determine the success of Strategy Implementation in the Insurance Industry. The study discerned that the strategy chosen on advertising and promotion affects the strategic desicions. Nonetheless, Nduati (2014), studies on strategy implementation at Kenya accountants and secretaries' national examinations board KASNEB revealed that it uses an implementation matrix, there is management commitment and that there is frequent monitoring and evaluation as strategy implementation progresses.

Wainaina (2014), researched on strategy implementation and performance of firms in telephony industry in Kenya, all the above local studies have covered strategic implementation in different sectors but scanty studies been specifically done on strategy implementation on maritime cluster. The study established that top management support acted as propelling force in every stage of strategy implementation process. For successful implementation stability between strategy and other organization dimension like organization culture, structure, reward structure, and resource allocation has to be achieved. Further examining the theories guiding the study in depth can bring a connection between the theoretical framework and in the current study, hence further guide on the gaps existing in the specific selected maritime clusters in Kenya while retaining the significance of the influence of both international and continental set ups.

\section{Research gaps}

Despite a number of research studies on strategy implementation, divergent views have been presented on the effects of several variables on strategy implementation since there is little evidence on the actual factors that influence strategy implementation (Okumu's, 2001). Sorooshian et al., (2010) did an empirical study of the relationship between strategy implementation and performance in SME's operating in Iran using empirical data sources. Sorooshian et al., (2010) explored the relationship between three major factors in strategy implementation (Leadership styles, Human Resource Management and Structure). The study did not focus on technology as a major driver enhancing firm's performance.

Further, Rajasekar (2014); Usman, Kamau and Mireri, (2014); Ansah (2017), the researchers did their research on influence of strategy implementation but did not examine the influence of strategy implementation within the Kenyan Maritime sector. In Kenya, a number of the past studies have mainly focused on the nexus between strategic planning practices and performance of a firm. Only a handful focuses on the influence of strategy implementation and organization's performance (Awino, 2013; Bowen et al., 2009; Bunyasi, Bwisa \& Namusonge, 2014; Gathogo \& Ragui, 2014; Gakure \& Amure, 2013; Kiganane, Bwisa \& Kihoro, 2012; Mosoti \& Murabu , 2014; Mwangi, 2012; Okwachi et al., 2013; Oseh, 2013) and this gap requires further investigation. None of the above studies sought to examine the performance of the local maritime clusters, which is indicating a literature gap.

Extensive literature from the reviewed studies has indicated that successful strategy implementation enhances the competitiveness and performance of firms. However, from the study by Mbaka and Mugambi (2014) it is evident that most state firms within the Kenya are prone to bureaucratic tendencies and resource wastage, which dampens the processes of strategy implementation. The study however only focussed on the Water Sector and did not explicitly consider the maritime sector as whole; thus, findings may not be reflective of the research focus. 


\begin{tabular}{|c|c|c|c|c|}
\hline Author & Variables & Methodology & Key Findings & Research Gap \\
\hline $\begin{array}{l}\text { Ansah, (2017). } \\
\text { Strategic planning } \\
\text { and performance of } \\
\text { micro and small } \\
\text { family businesses } \\
\text { in Ghana. The } \\
\text { resource based } \\
\text { approach }\end{array}$ & $\begin{array}{l}\text { Independent: } \\
\text { Strategic planning, } \\
\text { managerial } \\
\text { capabilities and } \\
\text { resource } \\
\text { allocation } \\
\\
\text { Dependent: } \\
\text { Performance of } \\
\text { micro and small } \\
\text { family business }\end{array}$ & $\begin{array}{l}\text { The study adopted } \\
\text { Convenience } \\
\text { random sampling. } \\
\text { The study adopted } \\
\text { a hierarchical } \\
\text { regression model } \\
\text { and exploratory } \\
\text { factor analysis }\end{array}$ & $\begin{array}{l}\text { The key findings } \\
\text { of the study was } \\
\text { that a managerial } \\
\text { capability and } \\
\text { resource } \\
\text { allocation had a } \\
\text { significantly high } \\
\text { positive } \\
\text { influence on } \\
\text { strategic } \\
\text { planning and firm } \\
\text { performance }\end{array}$ & $\begin{array}{l}\text { This study only } \\
\text { adopted a multiple } \\
\text { regression analysis } \\
\text { and did not take into } \\
\text { consideration the } \\
\text { observation of the end } \\
\text { consumers. } \\
\text { It only targeted CEO's } \\
\text { whereas this study will } \\
\text { take into consideration } \\
\text { the views of all } \\
\text { personnel at three } \\
\text { level of management. }\end{array}$ \\
\hline $\begin{array}{l}\text { Muthoka, Oloko, and } \\
\text { Obonyo, (2017) } \\
\text { Effect of Change } \\
\text { Management Driver } \\
\text { on } \\
\text { Performance of } \\
\text { Tourism State } \\
\text { Owned Firms In } \\
\text { Kenya. }\end{array}$ & $\begin{array}{l}\text { Independent: } \\
\text { Management } \\
\text { Change Driver; } \\
\text { clear vision, } \\
\text { organization } \\
\text { structure, } \\
\text { organization } \\
\text { culture) } \\
\text { Dependent: } \\
\text { Performance of } \\
\text { tourism state } \\
\text { owned firms in } \\
\text { Kenya. }\end{array}$ & $\begin{array}{l}\text { The study } \\
\text { employed } \\
\text { descriptive and } \\
\text { cross sectional } \\
\text { Study designs. } \\
\text { The study further } \\
\text { employed census } \\
\text { Sampling. }\end{array}$ & $\begin{array}{l}\text { The key findings } \\
\text { of the study was } \\
\text { that change } \\
\text { management } \\
\text { driver and } \\
\text { organization } \\
\text { Culture had a } \\
\text { higher positive } \\
\text { relationship to } \\
\text { the firm } \\
\text { performance. }\end{array}$ & $\begin{array}{l}\text { The study considered } \\
\text { only cruise tourism } \\
\text { firms whereas this } \\
\text { study will cover } \\
\text { strategy } \\
\text { implementation and } \\
\text { performance of the } \\
\text { entire maritime cluster } \\
\text { firms in Kenya and will } \\
\text { use both qualitative } \\
\text { and quantitative data } \\
\text { collection as well as } \\
\text { descriptive and } \\
\text { inferential statistics } \\
\text { analysis. }\end{array}$ \\
\hline $\begin{array}{l}\text { Rajasekar (2014) } \\
\text { Factors affecting } \\
\text { Effective Strategy } \\
\text { Implementation in a } \\
\text { Service Industry: } \\
\text { A Study of Electricity } \\
\text { Distribution } \\
\text { Companies in the } \\
\text { Sultanate of Oman }\end{array}$ & $\begin{array}{l}\text { Independent: } \\
\text { information } \\
\text { availability, } \\
\text { leadership style, } \\
\text { organizational } \\
\text { culture, } \\
\text { technology, } \\
\text { structure, human } \\
\text { resources } \\
\text { Dependent: } \\
\text { Strategy } \\
\text { implementation in } \\
\text { a service industry }\end{array}$ & $\begin{array}{l}\text { Descriptive study } \\
\text { that employed a } \\
\text { mixed } \\
\text { methodology }\end{array}$ & $\begin{array}{l}\text { The key findings } \\
\text { of the study were } \\
\text { that leadership } \\
\text { had the highest } \\
\text { influence on } \\
\text { strategy } \\
\text { implementation } \\
\text { than the other } \\
\text { factors }\end{array}$ & $\begin{array}{l}\text { The study considered } \\
\text { energy distribution } \\
\text { companies in Oman } \\
\text { whereas this study } \\
\text { considers maritime } \\
\text { cluster firms in Kenya }\end{array}$ \\
\hline $\begin{array}{l}\text { Usman, Kamau and } \\
\text { Mireri, (2014). } \\
\text { The influence of } \\
\text { implementation } \\
\text { phase principles on } \\
\text { project } \\
\text { performance within } \\
\text { the } \\
\text { building industry in } \\
\text { Abuja, Nigeria }\end{array}$ & $\begin{array}{l}\text { Independent: } \\
\text { Management, } \\
\text { budgetary } \\
\text { allocation, } \\
\text { planning and } \\
\text { project execution } \\
\text { Dependent: } \\
\text { Project } \\
\text { performance } \\
\text { in Building } \\
\text { industry }\end{array}$ & $\begin{array}{l}\text { The study adopted } \\
\text { both descriptive } \\
\text { and explanatory } \\
\text { approaches. Both } \\
\text { stratified and } \\
\text { random sampling } \\
\text { was adopted in the } \\
\text { Sample selection. }\end{array}$ & $\begin{array}{l}\text { Poor } \\
\text { management, } \\
\text { inadequate } \\
\text { budgetary } \\
\text { allocation and } \\
\text { poor plan } \\
\text { execution } \\
\text { resulted in poor } \\
\text { performance of } \\
\text { the project }\end{array}$ & $\begin{array}{l}\text { The study } \\
\text { considered project } \\
\text { performance whereas } \\
\text { the this study is } \\
\text { focused on an entire } \\
\text { Maritime sector. The } \\
\text { study did not consider } \\
\text { the effect of strategic } \\
\text { factors such as } \\
\text { information sharing, } \\
\text { culture and } \\
\text { organization structure. }\end{array}$ \\
\hline
\end{tabular}




\section{Chapter Summary}

The chapter shows studies focusing on factors such as "policies, leadership style, information availability and accuracy, uncertainty, organizational structure, resources capability, technology innovation" and their influence on implementation of strategic plans. There is general argument that each of those factors affects the process at a unique level and with a unique force. On the other hand, the choice of the maritime cluster and industrial cluster are justified as providing "a very attractive analytical base within a strategic management perspective, for many strategic aspects such as innovation, knowledge creation and diffusion, network economies have been found to bloom".

Review of the strategy implementation studies indicates that some remarkable progress has been made in developed world within the maritime clusters. However, there is scanty studies that have focus on influences or determinants of strategy implementation on organization performance in developing countries; hence, the problem of strategy implementation failure persists. Researchers and practitioners, therefore, have to make this their main priority. Most studies consider the failure to implement new strategies as a failure to improve the performance of a firm. The study on Kenya's maritime clusters shows that there is a gap in finding out the extent to which the stakeholder policy enforcers as well as players have gone in the implementation of such related policies whose findings can inform this study.

\section{Introduction}

\section{RESEARCH METHODOLOGY}

This chapter describes methodology that will be used to carry out the study which will include the research philosophy and the research design, the population, the sampling frame and sampling techniques of the study putting into perspective the study characteristics of data collection procedure and data collection instruments. In addition, the pilot testing will be done to test the research validity and reliability of data collection instruments, data analysis and data presentation to be used.

\section{Research Philosophy and Research Design}

Research design is the researcher's blueprint for answering the research questions Fiordelli, (Diviani, \& Schulz, 2013) and for the purposes of achieving the objectives of this study, the research will apply both qualitative and quantitative designs. Importantly, part of this study will apply the exploratory design which is guided by the philosophy of logical positivism based on the fact that a statement is only meaningful in the event that its validity can be proven (Gathenya, Bwisa \& Kihoro, 2012).

\section{The Research Philosophy}

Research philosophy is the foundation of knowledge on which underlying predispositions of a study are based (Saunders, Lewis \& Thornhill, 2015). These are positivism, realism, interprevitism, or pragmatism. Positivists' paradigm assumes that reality is fixed, directly measurable, and knowable and that there is just one truth, one external reality (Saunders, Lewis \& Thornhill 2009; Remenyi, Williams, Money \& Swartz, 2005). The purpose of paradigm is to generate hypotheses that can be tested; and to provide material for the development of laws (Bryman \& Bell, 2007). The positivism approach calls for the research to be conducted in a value free and in objective manner, independent of the subject of research. The product of research aims to be law, like generalizations similar to those that are produced by natural scientists, and positivism emphasizes quantifiable observations used for statistical analysis, which will be applied in the study (Saunders, Lewis \& Thornhill, 2009). This study will be guided by the positivist paradigm which is justified on the basis that the study is guided from a 
proposed theory of Higgins 8'S model from which specific hypotheses are drawn. This will lead to gathering of facts that will provide the basis for subsequent hypothesis testing. The choice is also justified by the fact that the respondents will be given the same set of questions to answer implying that the study assumes that the influence of strategy implementation on the maritime cluster performance is directly measurable, and well known (Gathenya, Bwisa \& Kihoro, 2012).

\section{Research Design}

A research design is a framework that guides the collection and analysis of the data. It shows, in detail how the study will conduct investigations in the research problem in an economic manner (Creswell \& Poth, 2017). This study will adopt both qualitative and quantitative data collection in a single study in which the study will collect data concurrently and will involve the integration of the data in one single stage of the research process (Creswell, 2013). The study is able to triangulate the empirical, constructs and the reality approaches thereby, bringing about validation of the variables, deepening and widening understanding of this area under investigation. Other researchers Sifa et al., (2009) used similar research design for similar studies. The study will adopt descriptive research designs in which the problem is clearly defined and the variables known (Sekaran \& Bougie, 2016). Cooper \& Schindler (2008) supports the view that when a research problem is well structured; hence a descriptive design is the most suitable method for solving it (Sekaran \& Bougie 2016). Therefore, by selecting this design will allow both the presentation of quantitative use of inferential statistics to test hypotheses for making predictions and qualitative descriptive data (Sifa et al., 2008).

\section{Target Population}

Target population is described as the entire group of people or things of interest for the study (Bryman \& Bell, 2015). The maritime sector in the country is comprised of 10 cluster categories consisting of various firms out of which some have achieved distinctive performance and growth. The study target population is 1386 infinite maritime firms. Therefore, according to Cooper and Schindler (2014), it is from the target population that samples are drawn. The study will target three levels of management teams from the sample of 94 firms as shown in figure 3.1

(KNBS, 2017), which are corporate, business, and functional levels, Higgins (2005) that will be the unit of analysis. Thus, the top management (corporate level) are the senior managers as strategy formulators and middle level managers (business level) are responsible for new product, innovation in research and development whereas, lower level managers (functional) are in areas like marketing, finance, operations, human resources management, R \& D, information, and logistics who are strategy implementer and based on the firms structure will be aligned to the study's sample size (Higgins, 2005). Thus, from each of selected firm, the study will target one respondent from each category of the corporate, business and functional levels that will form the 282 respondents of the study. 
Table 3.1: Target Population of Cluster Firms

\begin{tabular}{|c|c|c|c|}
\hline S/NO & $\begin{array}{l}\text { Strata } \\
\text { (cluster category) }\end{array}$ & Maritime type & $\begin{array}{l}\text { Firms-target } \\
\text { population }\end{array}$ \\
\hline 1 & $\begin{array}{l}\text { Cargo Handling } \\
\& \\
\text { Port Infrastructure }\end{array}$ & $\begin{array}{l}\text { - } \quad \text { Ports (Kilindini \& CFSs) } \\
\text { - } \quad \text { ICDs: Nairobi, Kisumu and Eldoret } \\
\text { - } \quad \text { Lamu including other Small Ports }\end{array}$ & $\begin{array}{c}34 \\
3 \\
5\end{array}$ \\
\hline 2 & Transport\& Storage & $\begin{array}{l}\text { - } \text { SGR/ Rift Valley Railway (Railways) } \\
\text { - } \text { Ferries (Kisumu } 3 \text { \& Mtongwe -1) } \\
\text { - } \text { KPRL \& KPLC }\end{array}$ & $\begin{array}{c}40 \\
1 \\
4 \\
2\end{array}$ \\
\hline 3 & $\begin{array}{l}\text { Third Party Freight } \\
\text { Logistics }\end{array}$ & $\begin{array}{l}\text { - Third Party Logistics \& Warehousing } \\
\text { - Shipping lines }\end{array}$ & $\begin{array}{c}950 \\
37\end{array}$ \\
\hline 4 & $\begin{array}{l}\text { Complementary } \\
\text { (Auxiliary) services }\end{array}$ & $\begin{array}{l}\text { - Banks } \\
\text { - Cargo Marine Insurance } \\
\text { - Bunkering services } \\
\text { - Supplies } \\
\text { - Ship's registry }\end{array}$ & $\begin{array}{c}42 \\
12 \\
4 \\
4 \\
1\end{array}$ \\
\hline 5 & Blue Economy & $\begin{array}{l}\text { Cruise } \\
\text { tourism/Fishing/sporting/Aquaculture/ } \\
\text { Ship building-repairs, Coastal mining }\end{array}$ & 6 \\
\hline 6 & $\begin{array}{l}\text { Safety, } \\
\text { Regulatory \& } \\
\text { Security }\end{array}$ & $\begin{array}{l}\text { KENHA, KMA, KATO, KRA, KPA, KTDA, } \\
\text { EPZA, Coffee Board (K), Port Health, Mines } \\
\text { and Geology, LCDA, NEMA, Kenya police, } \\
\text { KN, KGCS }\end{array}$ & 15 \\
\hline 7 & Trading & KPLC depots- 3, Refinery -1 & 4 \\
\hline 8 & Processing \& Trade & $\begin{array}{l}\text { - EPZ Companies and EEZ, } \\
\text { - Fishing \& Aquaculture processing } \\
\text { Firms } \\
\text { - Mining Firms }\end{array}$ & $\begin{array}{c}110 \\
18\end{array}$ \\
\hline 9 & $\begin{array}{l}\text { Mining (Minerals) } \\
\text { Off- shore Oil/Gas } \\
\text { Geothermal Power }\end{array}$ & $\begin{array}{l}\text { - Downstream \& distribution Upstream } \\
\text { \& exploration (Exploration and } \\
\text { Production) } \\
\text { - (E \& P), Energy (Geothermal, wind } \\
\text { power and solar) }\end{array}$ & $\begin{array}{l}14 \\
59 \\
12\end{array}$ \\
\hline 10 & $\begin{array}{l}\text { Training \& Research } \\
\text { Institutions }\end{array}$ & $\begin{array}{l}\text { JKUAT, NYS, Utalii College, Pwani } \\
\text { University, Bandari College, KMFRI, KWS, } \\
\text { KEFRI, KPLC } \\
\text { Total }\end{array}$ & $\begin{array}{c}9 \\
1386\end{array}$ \\
\hline
\end{tabular}

Source: (KNBS, 2017).

\section{Sample and sampling Technique \\ Sampling Frame}

A sample frame according to Johnson (2010) is list of all members of the population of interest, with the specific characteristics needed for the study. It has the property that the study can identify every single element and include any in the sample (Saunders et al., 2009). The study's sample frame will comprise strata of 94 firms as a sampling unit from the 1386 target population of maritime cluster firms that include: Service Providers (11) such as cargo handling and Port Operations; Transport services; infrastructure, transport and storage, complementary auxiliary- services (banks for instituting letter of credit and insurance 
companies for instituting cargo insurance marine cover); Safety, regulatory and security. Stakeholder include (81); freight logistics firms; minerals and mining; Processing firms; offshore oil/gas (P and E), and geothermal extraction. Training and research institutions (2); Maritime recreation /leisure sports/Cruise tourism; building and repairs, as shown in tables 3.2 and 3.3. That one respondent from each category of management will be picked from top management (corporate level), middle level managers (business level) and lower level managers (functional level) consisting of line managers or supervisors depending on the organizational structure of the firms). Thus, this covers all the functional areas that deal with strategy formulation, strategy implementation and strategy execution in order to achieve strategic organizational performance

Table 3.2 Target Sample Firms' Matrix

\begin{tabular}{|c|c|c|c|c|c|c|}
\hline $\begin{array}{l}\text { Study } \\
\text { Group }\end{array}$ & $\begin{array}{l}\text { Study } \\
\text { Clusters }\end{array}$ & $\begin{array}{l}\text { Target } \\
\text { Population }\end{array}$ & $\begin{array}{l}\text { Sample } \\
\text { Size }\end{array}$ & $\begin{array}{l}\text { Respondents } \\
\text { (Level) } \\
\text { Category }\end{array}$ & $\begin{array}{l}\text { Respondent } \\
\text { Per category }\end{array}$ & Respondent \\
\hline \multirow{3}{*}{$\begin{array}{l}\text { Maritime } \\
\text { cluster } \\
\text { firms in } \\
\text { Kenya }\end{array}$} & \multirow{3}{*}{10} & \multirow{3}{*}{1386} & \multirow{3}{*}{94} & $\begin{array}{l}\text { (Corporate level) } \\
\text { Top Management }\end{array}$ & 1 & 94 \\
\hline & & & & $\begin{array}{l}\text { (Business level) } \\
\text { Middle Level } \\
\text { Management }\end{array}$ & 1 & 94 \\
\hline & & & & $\begin{array}{l}\text { (Functional level) } \\
\text { Lower level } \\
\text { Management }\end{array}$ & 1 & 94 \\
\hline Total & 10 & 1386 & 94 & & 3 & 282 \\
\hline
\end{tabular}

\section{Sampling Technique}

According to Kothari (2012), sampling is the process followed in acquiring information about a target population or a proportion of it. Samples for scientific studies can be drawn using both probability and non-probability based methods (Saunders, Lewis \& Thornville, 2009). The sampling techniques that will be applied in this study are; random sampling and purposive sampling (Cooper \& Schindler, 2011). Random sampling will be applicable on choosing maritime cluster firms from each sample size category of firms for this study. This is because it is the least biased and offers the most generalization in each item from the Strata. In this case each firm will have equal opportunity of representation in the sample. The study will also utilize purposive sampling in selecting personnel who will be available, reliable and are knowledgeable about the area of the study on the strategy implementation and performance (Kothari (2012). This technique is used to select a unit of the population that is typical of the population based on the study's judgment on their typicality (Orodho, 2009).

\section{Sample size Determination}

In this case, stratified simple random sampling will be used to pick on the firms from each stratum (cluster) of the infinite population. Therefore, in this study the sample size (n) will be adjusted using Yamane formula (1967). This formula allows sample size calculation at 3\%, 5\%, $7 \%$ or $10 \%$ precision (e) level and $90 \%$ confidence level with degree of variability (p) equivalent to $50 \%(0.05)$. Therefore applying the sample size using the Yamane (1967) formula where;

$\mathrm{n}=$ Sample size

$$
\mathrm{n}=\mathrm{N} /\left(1+\mathrm{N} \times \mathrm{e}^{2}\right)
$$

$\mathrm{N}=$ target population 1386 
$e=\operatorname{margin}$ error $10 \%(e=0.01)$

In the proposed study, the sample size will be;

$\mathrm{n}=1386 /(1+1386 \times 0.01 \times 0.01)=1386 / 14.86=93.30$

A sample size of 94 firms will be targeted within the maritime sector in Kenya. The firms will be apportioned across the maritime clusters from which the sample size is obtained from each maritime cluster unit of the population as shown below in table 3.3.

Tale 3.3: Sampling size proportionate allocation

\begin{tabular}{|c|c|c|c|c|c|}
\hline $\begin{array}{l}\text { MARITIME } \\
\text { CLUSTERS } \\
\end{array}$ & CLUSTER TYPE & POPULATION & $N /\left(1+N \times e^{2}\right) n$ & $\begin{array}{l}\text { CLUSTER } \\
\text { TYPE SAMPLE } \\
\end{array}$ & $\begin{array}{l}\text { SAMPLE SIZE PER EACH } \\
\text { MARITIME CLUSTER }\end{array}$ \\
\hline $\begin{array}{l}\text { Cargo Handling \& Port } \\
\text { infrastructure }\end{array}$ & Service provider & 42 & & & $(42 \div 158) \times 11=3$ \\
\hline Transport \& Storage & & 47 & & & $(47 \div 158) \times 11=3$ \\
\hline $\begin{array}{l}\text { Complementary } \\
\text { (Auxiliary) Services }\end{array}$ & & 63 & $(158 / 1386)^{*} 93.30$ & 11 & $(63 \div 158) \times 11=4$ \\
\hline Blue Economy & & 6 & & & $(6 \div 158) \times 11=1$ \\
\hline $\begin{array}{l}\text { Third Party Freight } \\
\text { Logistics }\end{array}$ & Stakeholder & 987 & & & $(987 \div 1200) \times 81=66.7$ \\
\hline $\begin{array}{l}\text { Mining \& Extractive, } \\
\text { Off Shore oil /Gas } \\
\text { Geothermal wind }\end{array}$ & & 85 & $1200 / 1386 * 93.30$ & 81 & $(85 \div 1200) \times 81=5.7$ \\
\hline Power and Solar energy & & & & & \\
\hline Processing \& Trade & & 128 & & & $(128 \div 1200) \times 81=8.64$ \\
\hline $\begin{array}{l}\text { Safety, Regulatory \& } \\
\text { Security }\end{array}$ & Training & 15 & & & $(15 \div 28) \times 2=1$ \\
\hline Training \& Research & & 9 & $28 / 1386 * 93.30$ & 2 & $(9 \div 28) \times 2=1$ \\
\hline Building \& Repairs & & 4 & & & $(4 \div 28) \times 2=0$ \\
\hline Total & & 1386 & & 94 & 94 \\
\hline
\end{tabular}

\section{Data Collection Instruments}

Primary data will be collected through questionnaire based on a 5-point Likert scale with mixed closed and open-ended questions targeting corporate management of the stakeholders in the maritime cluster groups as shown in table3.3. These are the preferred methods since they are easy to administer and time-saving (Mugenda \& Mugenda, 2008). Each item on the questionnaires are developed on specific objectives of the study, which will be selfadministered to the respondents in accordance with (Orodho, 2008). The study will also make use of key informant interviews from the maritime cluster firms' management of service providers table 3.3. Further, secondary data for this study will be collected through reviews of maritime studies of professional journals, textbooks and e-books for analysis purpose (appendix iii). The advantage of the secondary data is to compare findings from the field with the existing body of knowledge. The combination of the findings are for better understanding of the problem and to enhance existing body of knowledge as reviewed from the different sources to either corroborate or disagree with the findings (Creswell, 2013).

\section{Data Collection Procedure}

Data collection is defined as precise, systematic gathering of information relevant to research problem by use of methods such as interviews, participant observation, narrative or case histories (Burns \& Grove, 2003). The management of the maritime cluster firms will be the target group and will be contacted for appointment or permission to allow data collection. An introductory letter from the university (JKUAT) and permit from National Commission for 
Science, Technology and Innovation (NACOSTI) will be obtained before proceeding to the field for data collection. The study will seek the services of eight (8) research assistants who will be trained on the use of study research tools and will be regularly supervised to insure consistency and assistance that may be required during the entire period of data collection. The study envisions collecting the data for this study during the months of April to May, 2018 for the period of 30 days.

Both quantitative and qualitative data collections will be used for the study from the respondents and the management team in the maritime cluster firms is the target group. The data collection will be through questionnaires and by face-to-face interviews. The questionnaires will be self-administered by drop, and pick method, each respondent will receive verbal instructions asking them to complete the questionnaires anonymously, whereas document analysis guide be used for gathering the secondary data and enough time will be granted to respond to all the questionnaires.

\section{Pilot Testing}

Pilot testing will be undertaken to support reliability and validity (Kothari, 2004). Pilot testing is to ascertain the reliability and validity of the research instruments before being administered to the target population. The study will be conducted with $10 \%$ of the total sample size of 94 maritime cluster firms that will not be included in the final research. This is in accordance with recommendations by (Bryman \& Bell, 2015). Pilot testing will provide an opportunity to detect and remedy any potential problems with the research instruments (questionnaires).

\section{Validity of Research Instruments}

According to Field (2009), determining the accuracy of the scale measurements in a research instrument is of great importance in scientific studies. The study will employ both construct and content validities and will use confirmatory factor analysis to test for validity.

For construct validity, the study will align the research instruments with the research objectives by use of factor analysis whereas in conducting content validity, the study will seek the assistance of the supervisors. Saunders et al (2009) define content validity as the extent to which the measurement tool provides adequate coverage of the investigative questions. Construct validity therefore refers to the extent to which the measurement questions actually measure the presence of the constructs intended to be measured (Saunders et al., 2009). Whereas according to Cooper \& Schindler (2014), construct validity entails looking at both the theory and the measuring instrument being used.

\section{Reliability of Research Instruments}

The reliability test is conducted to measure whether the research instrument will provide the same results each time the instrument is used among the sample respondents. Reliability problems may arise when studies tend to overstate the importance of the data obtained or the sample is too restricted (Sullivan, 2011). The common method for testing the reliability of a research instrument is by using the Cronbach Alpha's reliability coefficient, $\alpha$, will be used for internal reliability test. The coefficient normally ranges between 0 and 1 although actually no lower exists. The closer $\alpha$, is to 1.0 the greater the internal consistency of the items in the scale. The size of $\alpha$ will be determined by both the number of items in the scale and the mean interitem correlations based upon the formula:

$$
\alpha=\left[\frac{r k}{\left(1+\frac{k-1}{r}\right)}\right]
$$


Where: $\mathrm{K}=$ is the number of items considered and $\mathrm{r}=$ is the mean of inter-item correlations. George and Malley (2003) as cited in Wanjala, Iravo, Odhiambo and Shalle (2017) provide the following commonly accepted rules of thumb for alpha values:

$\alpha \geq 0.9$ - Excellent ; 0.9 . $>\alpha \geq 0.8$ - Good; $0.8 \geq \alpha \geq 0.7$ - Acceptable; $0.7>\alpha \geq 0.6$ - Questionable; 0.6. $>\alpha \geq 0.5$ - Poor and $0.5>\alpha$ - unacceptable. Therefore, ideally the Cronbach Alpha Coefficient of the scale should be at least acceptable, that is, above 0.7 (Bryan, 2014).

\section{Data Analysis}

The study will employ both descriptive and inferential statistics and will further undertake diagnostics tests to ensure accuracy and fitness of the data by testing of the hypothesis developed (Sekaran, 2006). The quantitative data analysis will involves a series of statistical activities generated by Statistical Package for Social Science SPSS such as mean, percentages, variances, figures, charts, T-test and infographics to give expected summary of variables being studied for ease of interpretation and presentation whereas qualitative data will be presented through narratives in line with the research objectives.

The collected qualitative data will be analysed using content analysis in line with the study objectives and will be presented in form of frequency, mean, measurement of relationship and standard deviation. The resultant thematic contents analysis and patterns will be assigned numbers for measurement purposes.

Both inferential and descriptive statistics methods will be used to analyse data obtained from the questionnaire using SPSS (version 22.0) to give expected summary of variables of the study. The study will triangulate both qualitative and quantitative data from the respondents who will answer the questionnaire. To test the significance of the relationship between variables, the study will use both correlation and regression analyses. Inferential Statistics will measure the relationship between the independent variables and dependent variable by use of a multiple regression. Mugenda and Mugenda (2008) assert that multiple regression analysis attempts to determine whether a group of variables together predicts a given dependent variable and in this way, attempt to increase the accuracy of the estimate.

\section{Descriptive Statistics analysis}

In this case, descriptive statistics will be used to give information that describes the data. The results will be represented through the use of graphs, charts and tables such as histograms, bar graphs and pie graphs. This method will ensure that the data is described by compiling it into a graph, table or other visual representation. This will provide an easier method for making comparisons between different data sets and to spot the smallest and largest values and trends or changes over a period of time.

\section{Inferential Statistics Analysis}

The research will use regression analysis to assess the relationship between the independent variables and dependent variable using SPSS version 24.0 and regression analysis to be used will be:

$$
Y=\alpha+\beta_{1} X_{1}+\beta_{2} X_{2}+\beta_{3} X_{3}+\beta_{4} X_{4}+\beta_{5} X_{5}+\varepsilon
$$

Where: $\mathrm{Y}=$ Dependent Variable (organizational performance)

Independent variables, which include:

$\mathrm{X}_{1}$ is strategic policies

$\mathrm{X}_{2}$ is Organization Structure 
$\mathrm{X}_{3}$ is Resource Capability

$\mathrm{X}_{4}$ is System and Processes

$\mathrm{X}_{5}$ is strategic direction

$\alpha=$ the constant $=Y$ intercept

$\beta_{1-5}=$ the regression coefficient or change included in $Y$ by each $X$

$\epsilon=$ error term

The closer the p-values of the regression results are closer to +1 the higher the association between the research variables.

\section{Moderating Variable Analysis}

The moderated multiple regression model will be;

\section{Where;}

$$
\mathbf{Y}=\alpha+\mathbf{b X}+\mathbf{c Z}+\mathbf{d X} \mathbf{X}^{*} \mathbf{Z}+\boldsymbol{\varepsilon}
$$

$Y=$ Organization performance

$\mathrm{X}=$ Aggregate influence of strategy implementation

$\mathrm{Z}=$ Hypothesized moderation of size and age of organization on relationship between $\mathrm{X}$ on $\mathrm{Y}$

$\mathrm{dX}^{* \mathrm{Z}}=$ The composite influence of strategy implementation and firm characteristics on organization performance.

$\varepsilon=$ Error term

\section{Data processing}

The t-test will be used to determine the relationship between each individual independent variable and the dependent variable. The $\mathrm{F}$ - test will be used to determine the overall relationship between the dependent and all the independent variables.

\section{Statistical Tests}

In this study, the hypothesis testing will be carried out by using both t-test and F-test statistical tools with 0.05 significance level. Once the model is analysed, value of 0.05 and obtained for each hypothesis and a P-value then the hypothesis will be rejected. The purpose of hypothesis testing is to determine the accuracy of the study hypotheses because the researcher has collected a sample of data, not a census (Cooper \& Schindler, 2008).

\section{Hypothesis Testing}

The study will adopt statistical tests such as ANOVA (Goodness of Fit Tests) and independent ttests at a 95\% Confidence level. The statistical tests will enable the study to accept or reject the research hypotheses based on the statistical significance of the results. The closer the statistical values will be to 1 the higher the statistical association between the variables.

\section{Diagnostic Tests}

This section contains diagnostics tests for testing regression assumptions, which include; Linearity, Normality, Heteroscedasticity, Multicollinearity and Tests of Independence (Autocorrelation) as shown in table 3.4. 
Table 3.4 Diagnostics test

\begin{tabular}{|c|c|c|c|}
\hline Test & Significance & Test used & Conclusion \\
\hline Normality & $\begin{array}{l}\text { Help in knowing the shape of the } \\
\text { distribution and helps to predict } \\
\text { dependent variables scores }\end{array}$ & $\begin{array}{l}\text { Shapiro-Wilk test } \\
\text { Quartile-Quartile } \\
\text { Plot (Q-Q plot) }\end{array}$ & $\begin{array}{l}\text {-If P-value }<0.05 \text {, data is } \\
\text { normally distributed } \\
\text { For the fit to be done, the } \\
\text { dependent variable } \\
\text { scatter should be } \\
\text { normally distributed }\end{array}$ \\
\hline Heteroscedasticity & $\begin{array}{l}\text { Checks whether the variance of } \\
\text { the dependent variable varies } \\
\text { across the data (test the } \\
\text { assumption of equal variance) }\end{array}$ & Glejser test & $\begin{array}{l}\text { If } \mathrm{P} \text {-value }<0.05 \text {, presence } \\
\text { of non-uniform variance }\end{array}$ \\
\hline Multicollinearity & $\begin{array}{l}\text { Check whether the correlations } \\
\text { among the independent variables } \\
\text { are strong }\end{array}$ & $\begin{array}{l}\text { Variance } \\
\text { Inflation Factor } \\
\text { (VIF) }\end{array}$ & $\begin{array}{l}\text { If VIF for one of the } \\
\text { variables is around or } \\
\text { greater than } 10 \text {, there is } \\
\text { Multicollinearity }\end{array}$ \\
\hline $\begin{array}{l}\text { Tests of } \\
\text { Independence } \\
\text { (Autocorrelation) }\end{array}$ & $\begin{array}{l}\text { check that the residuals of the } \\
\text { models were not auto correlated } \\
\text { (Checks for independence of error } \\
\text { terms, which implies that } \\
\text { observations are independent }\end{array}$ & $\begin{array}{l}\text { Durbin Watson } \\
\text { (DW) test }\end{array}$ & $\begin{array}{l}\text { Scores between } 1.5 \text { and } \\
2.5 \text { indicate independent } \\
\text { observations }\end{array}$ \\
\hline
\end{tabular}

\section{Operationalization of variables}

Operationalization of variables table shows the relationship between strategy implementation independent variables and dependent variable on performance of Maritime cluster firms in Kenya. The dependent variable is the performance that will be measured against independent variables; strategic policies, organizational structure, Resource capability, Technology innovation, firms' size and years of operation, and performance of maritime cluster firms in Kenya as shown in table 3.5

\section{Data Presentation}

This study's results and findings will be presented by use of graphs, pie charts and tables. In this case, the use of frequency table will help in presenting data by assigned numerical value that shows percentages, valid percentages as well as cumulative percentages. The presentation percentages especially when indicated in graphic format are easily seen and understood (Cooper \& Schindler, 2011). 
Table 3.5 Operationalization of Variables

\begin{tabular}{|c|c|c|c|}
\hline Research Hypothesis & Measurement & Analysis techniques & Interpretation \\
\hline $\begin{array}{l}\text { Influence of strategy } \\
\text { implementation on } \\
\text { performance of } \\
\text { maritime cluster firms in } \\
\text { Kenya. } \\
\text { All the independent } \\
\text { Variables collectively } \\
\text { and significantly } \\
\text { influence the Dependent } \\
\text { Variable }\end{array}$ & $\begin{array}{l}\text { Quantitative } \\
\text { Data } \\
\text { Qualitative } \\
\text { 5Point-Likert } \\
\text { Scale }\end{array}$ & $\begin{array}{l}\text { Multiple Regression analysis } \\
Y=\alpha+\beta_{1} X_{1}+\beta_{2} X_{2}+\beta_{3} X_{3}+\beta_{4} X_{4}+ \\
\left.\beta_{5} X_{5}+\varepsilon\right) \\
Y=\text { Performance of maritime } \\
\text { cluster in Kenya } \\
\alpha=\text { constant (intercept) } \\
X_{1-=} \text { is the composite index of } \\
\text { stakeholders' engagement } \\
X_{2=\text { is the composite index of }} \\
\text { organizational structure } \\
X_{3} \text { is, the composite index of } \\
\text { strategic } \\
X_{4}=\text { is the composite index of } \\
\text { resource capability } \\
X 5=\text { is the composite index of } \\
\text { strategic direction }\end{array}$ & $\begin{array}{l}\text { All the independent } \\
\text { variables } \\
\text { collectively } \\
\text { influence the } \\
\text { dependent variable }\end{array}$ \\
\hline & & $\begin{array}{l}\beta_{1-} \beta_{4-\text { are the coefficients }} \\
\varepsilon \text {-is the error term }\end{array}$ & $\begin{array}{l}\text { Compute P Value } \\
\text { given by SPSS. }\end{array}$ \\
\hline $\begin{array}{l}\text { Ha1 Strategic Policies } \\
\text { have significant } \\
\text { Influence on } \\
\text { Performance of } \\
\text { maritime } \\
\text { cluster firms in Kenya. }\end{array}$ & $\begin{array}{l}\text { Quantitative } \\
\text { Data } \\
\text { Qualitative } \\
\text { 5Point-Likert } \\
\text { Scale }\end{array}$ & 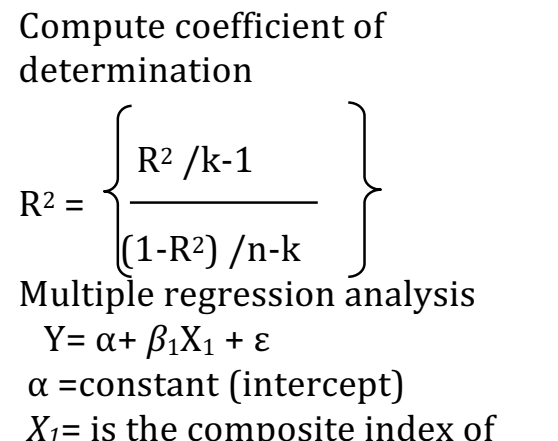 & $\begin{array}{l}\text { If } \mathrm{P} \leq \alpha / 2 \text {, then } \\
\text { there is a significant } \\
\text { relationship } \\
\text { between strategic } \\
\text { policies and } \\
\text { performance of } \\
\text { maritime cluster } \\
\text { firms in Kenya. } \\
\text { Compute P Value }\end{array}$ \\
\hline $\begin{array}{l}\text { Ha2Organizational } \\
\text { structure has significant } \\
\text { influence on } \\
\text { performance of } \\
\text { maritime cluster firms } \\
\text { in Kenya. }\end{array}$ & $\begin{array}{l}\text { Quantitative } \\
\text { Data } \\
\text { Qualitative } \\
\text { 5Point-Likert } \\
\text { Scale }\end{array}$ & $\begin{array}{l}\text { strategic policies } \\
\varepsilon=\text { Error term } \\
\text { Compute the P-value } \\
\text { corresponding to } \beta_{1} \\
\text { If } \mathrm{P} \text {-value } \leq \frac{\alpha}{2} \text { reject } \mathrm{H}_{0} \\
\text { Multiple Regression analysis } \\
\mathrm{Y}=\alpha+\beta_{2} \mathrm{X}_{2}+\varepsilon \\
\alpha=\text { constant (intercept) } \\
X 2=\text { is the composite index of } \\
\text { strategic leadership }\end{array}$ & $\begin{array}{l}\text { given by SPSS. If } P \leq \\
\alpha / 2 \text {, then there is a } \\
\text { significant } \\
\text { relationship } \\
\text { between } \\
\text { organization } \\
\text { structure and } \\
\text { performance of } \\
\text { maritime cluster } \\
\text { firms in Kenya }\end{array}$ \\
\hline $\begin{array}{l}\text { Ha3 There exists } \\
\text { significant influence of } \\
\text { resource capabilities on } \\
\text { performance of } \\
\text { Maritime cluster firms in } \\
\text { Kenya }\end{array}$ & $\begin{array}{l}\text { Quantitative } \\
\text { Data } \\
\text { Qualitative } \\
\text { 5Point-Likert } \\
\text { Scale }\end{array}$ & $\begin{array}{l}\varepsilon=\text { Error term } \\
\text { Compute the P-value } \\
\text { corresponding to } B_{2} \\
\text { If } \mathrm{P} \text {-value } \leq \frac{\alpha}{2} \text { reject } \mathrm{H}_{0} \\
\text { Multiple Régression analysis } \\
\mathrm{Y}=\alpha+\beta 3 X 3+\varepsilon \\
\alpha=\text { constant (intercept) } \\
X_{3}=\text { is the composite index of } \\
\text { organization structure } \\
\varepsilon=\text { Error term } \\
\text { Compute the P-value }\end{array}$ & $\begin{array}{l}\text { Compute P Value } \\
\text { given by SPSS. } \\
\text { If } \mathrm{P} \leq \alpha / 2 \text {, then } \\
\text { there is a significant } \\
\text { relationship } \\
\text { between Resource } \\
\text { capability } \\
\text { and performance of } \\
\text { maritime cluster } \\
\text { firms in Kenya. }\end{array}$ \\
\hline
\end{tabular}




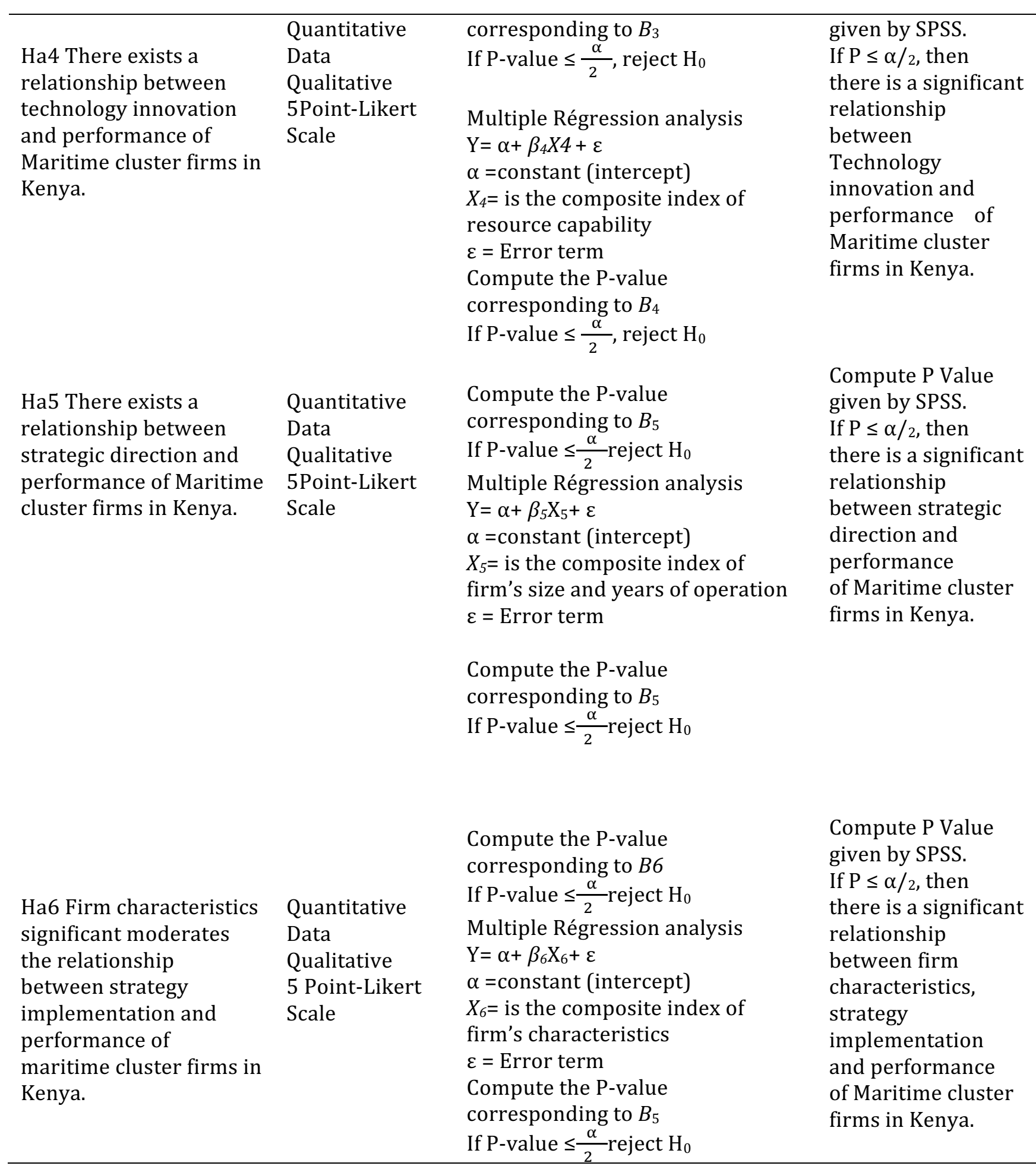




\section{References}

Abass, M. K., Munga, J., \& Were, E. (2017). The relationship between strategy Implementation and performance in county governments of Kenya: A case study of Wajir County government. International Academic Journal of Human Resource and Business Administration, 2(3), 381-401.

Abdullahel, B. (2018). Our Oceans and Blue Economy : Opportunities and Challenges. Elsevier, Procedia Engineering Vol. 194, 2017 (5-11).

AKI. (2016). Annual Insurance Report. Association of Kenya insurers Retrieved from

[http://www.akinsure.com/images/report/AKI\%20Annual\%20.Report\%202015\%20 final]

Alam, S., \& Islam, M. (2017). Impact of Blue Ocean Strategy on Organizational Performance A literature review toward implementation logic. ssrn papers.

Alharthy, A. H., Rashid, H., Pagliari, R., \& Khan, F. (2017). Identification of strategy Ijbssnet journal 8 (1)

Ali, A. (2013). Significance of human resource management in organizations. Retrieved from http://papers.ssrn.com/

Allio, M. (2005). A Short, Practical Guide to Implementing Strategy. Journal of Business Strategy,,26 (4), 2005,12 21.

Andreou, P. C., Louca, C., \& Panayides, P. M. (2014). Corporate governance, financial Management decisions and firm performance: Evidence from the maritime industry. Transportation Research Part E: Logistics and Transportation Review, 63, 59-78.

Arne, Isaksen, Stig-Erik Jakobsen. (2017). New path development between innovation Systems and individual actors. European Planning Studies 25:3, pages 355-370.

Ansah, J. K. (2017). Strategic planning and performance of micro and small Family Bsuiness in Ghana. The resource based approach. Doctoral dissertation.

Armesh, H, Salarzehi,. H, Kord. B. (2010). Institute of Interdisciplinary Business Research 193 October 2010 VOL 2, NO 6 Management Control System Faculty of Management, MMU,University of Sistan and Baluchestan Malaysia

Ashkenas, R., Ulrich, D., Jick, T., \& Kerr, S. (2015). The boundary less organization Breaking: the Chains of organizational structure. John Wiley\& Sons.

Atkinson, H. (2006). Strategy implementation: a role for the balanced Scorecard? Management Decision. , 44 (10), $1441-1460$.

AU. (2012). 2050 Africa's Integrated Maritime Strategy. Retrieved on 20.06.2017 from

https://wedocs.unep.org/bitstream/handle/20.500.11822/11151/2050_aim_srategy.pdf?sequence=1\&isAllowed $=\mathrm{y}$

Awino, Z. B., Njeru, W. G., \& Adwet, K. (2017). Strategy Implementation:Mckinsey's7s Framework Configuration And Performance Of Large Supermarkets In Nairobi, Kenya. Archives of Business Research, , 5(6).

Banerjee, A., Chitnis, U., Jadhav, S., Bhawalker, J., \& Chaudhury, S. (2009). Hypothesis testing, type I and type II errors. Industrial Psychiatry Journal. 18(2) 127-131.

Barnat, R. (2012). Introduction to Management. Retrieved on 26/06/2015 from http://www.introduction-tomanagement.24xls.com/

Barney. J. B. (2001). "Is the resource-based “view "a useful perspective for strategic Management research? Yes" . Academy of Management Review, 26, (1) 41-56.

Barney, J. (2001). Resource -based theories of competitive advantage: a ten year retrospective on the ResourceBased View. Journal of Management 27, 643- 650.

Barney, J. B., \& Clark, D. N. (2007). Resource-based theory: Creating and sustaining Competitive advantage. Oxford University Press on Demand.

Baker, M. L. (2011). 'Toward an African Maritime Economy. Empowering the African Union to Revolutionize the African Maritime Sector', Naval War College Review, 2.: 39- 62.

Barreto, I. (2010). Dynamic capabilities: A review of past research and an agenda for the future Journal of Management, 36(1), 256-280.

Baum, J., \& Rowley, J. (2005). Companion to organizations, 2nd Rev.,UK: Wiley Black well

Belgraver. H. \& Verwaal. E., (2017). Organizational capital, production factor resources. And relative firm size in strategic equity alliances Springer Science \& Business Media New York 2017 
Bell, T. S. (2007). Deep-level composition variables as predictors of team performance: a Meta -analysis. Journal of Applied Psychology, 92 (3), 595 - 615.

Bhatti, O. K. (2011). Strategy implementation: an alternative of 8S's. Annals of Management Research, 1(2), 52-59.

Bhimani, A., \& Langfield-Smith, K. (2007). Structure, formality and the importance of Finacial and non-financial information in strategy development and implementation. Management Accounting Research, 18(1), 3-31.

Bowman, C., \& Ambrosini, V. (2015). How the resource-based and the Dynamic Capability views of the firm inform corporate-level strategy. British Journal of Management, 14(4), 289-303.

Bradford, A. (2015). What is a scientific hypothesis? Definition of a hypothesis. Retrieved on 23/07/2014 from [http://www.livescience.com/21490-what-is-a-scientific-pothesis-definition-of-hypothesis.html/]

Brannen.J.(2005).Mixing Methods: The Entry of Qualitative and Quantitative Approaches into the Research Process . International Journal of Social Research Methodology, 8 (3),173 - 18412.

Briel, M.(2014). Strategic Performance Management using Balanced Scorecard Approach, Doctoral dissertation, University of Pretoria. Faculty of Engineering Built Environment and Information Technology. Dept. of Industrial and Systems Engineering)

Brown, J. S., \& Duguid, P. (2017). The Social Life of information: Updated with a Newpreface Harvard Business Review Press.

Bryman, \& Bell, E. (2015). The nature of quantitative research. In:BusinessResearch Methods New York : Oxford University Press.

Bueger, C. (2013). Communities of security practice at work? The emerging Africa Maritime Security regime. African security, 6(3-4), 297-316.

Burns, N., \&Grove, S. K. (2003). The practice of Nursing Research: Conduct, Critique and Utilization. Philadelphia: W. Saunders.

Bums, T., \& Stalker, G. M. (2012). The Management of Innovation. Tavistock, London.

Caffrey, E., \& McDonagh, J. (2017). A Perspective on the Roles of MiddleManagers in Aligning Strategy and Information Technology in Public Service Organizations. In informa tion Technology Governance in Public Organizations. pp. 59-83

Candido, J., \& Santos, P. (2015). Strategy implementation: What is the failure rate? Journal of Management \& Organization, 21(2), 237-262

Carpenter, M. A., \& Sanders, G. W. (2013). Upper echelons research revisited: antecedents, elements, and consequences of top management team composition. Journal of Management, 30(6), 749 -778

Cater, T., \& Pucko, D. (2010). Factors of effective strategy implementation: Empirical evidence from Slovenian business practice. Journal for East European Management Studies, 15(3), 207-236.

Chang, S., \& Tharenou, P. (2004). Competencies needed for managing a Multicultural Work group. Asia Pacific Journal Human Resources, 42, 57-74

Chaudhry, A., Yuan, L., Hu, J., \& Cooke, R. A. (2016). What matters more? The impact of industry and organizational factors on organizational culture. Management Decision, 54(3), 570-588.

Chelte, A. (2014). Strategy implementation: Organizing for action. Western NewEngland College Prentice

Chen, J. S., \& Tsou, H. T. (2007). Information technology adoption for ServiceInnovation Practices and competitive advantage: The case of financial firms. Information research. An international electronic journal, 12(3), n3.

Cheng, J. W., Chiu, W. L., Chang, Y. Y., \& Johnstone, S. (2014). Do you put your best foot forward? Interactive effects of task performance and impression management tactics on career outcomes. The Journal of psychology, 148(6), 621-640.

Chenhall, R. H. (2003). Management control systems design within its Organizational Context findings from contingency-based research and directions for the future. Accounting, Organizations and society.

Chimhanzi, J., \& Morgan, R. E. (2005). Explanations from the marketing/human resources: Dyad for Marketing strategy implementation effectiveness in service firms. Journal of Business Research, 58(6), 787-796.

Chorn, N. H. (1991). The "alignment" theory: Creating strategic fit. Management Decision, , 29(1). 
Chung, Y., Hsu, Y., Tsai, S., Huang, H., \& Tsai, C. (2012). The correlation between Business Strategy, Information technology, Organizational Culture, Implementation of CRM and Business Performance in a high tech Industry. South African Journal of Industrial Engineer. 23 (2).

Cooper, D. R., \& Schindler, P. S. (2014). Business Research Methods (Twelfth ed.). Boston: Irwin McGraw Hill International

Courson, E. (2009). Movement for the emancipation of the Niger Delta (MEND): Political marginalization, repression and petro-insurgency in the Niger Delta. The Nordic Africa Institute. Retrieved from http://www.divaPortal.org/smash/get/diva2:280 470 FULLTEXT01.pdf

Creswell, J. W.(2013). Advances in Mixed Methods Research - John Wiley \& Sons, UK

Creswell, PhD - keynote at the 2016 CAQD conference.

Creswell, J. W., \& Poth, C. N. (2017). Qualitative inquiry and research design: Choosing a mong five approaches. Sage publications.

Crittenden, \& Crittenden, W. (2008). Building a capable organization: The eight levers of Strategy Implementation. Business Horizons, 51 (4), 301-309

Dale, Van Der Wiele, \& Iwaarden, V. (2007). Managing quality. John wiley \& Sons Ltd.

Dandira, M. (2011). Involvement of implementers: missing element in strategy Formulation Business strategy series, 12(1), 30-34.

Dannenmaier, R. (2007). TOP - Transformation Optimizing Process. Version 4, ifss - Institute for Six Sigma, Vienna.

Dewett, T., \& Jones, G. R. (2001). The role of information technology in the Organizational review, model, and assessment. Journal of management, 27(3), 313-346.

Doloreux, D., \& Melançon, Y. (2008). On the dynamics of innovation in Quebec's Coastal maritime industry. Technovation, 28(4), 231-243.

Donaldson, L., (2001). The Contingency Theory of Organizations. Sage, Thousand Oaks

Easterby-Smith, M., Lyles, M. A. and Peteraf, M. A. (2009), Dynamic Capabilities: Current Debates and Future Directions. British Journal of Management, 20: S1-S8. doi:10.1111/j.1467-8551.2008.00609

Eisma-Osorio, R. L. \& G. K., Mahon, R.(2009). Tropical marine EBM Feasibility: a synthesis of case studies and comparative analyses. Coastal Management, 37(3-4), 374-385.

Enright,M.(2010). Regional clusters and multinational enterprises: Independence, Dependence or Interdependence?International Studies of Managemnt \& Organization, 30(2), 114-138.

Eroke, L. (2013). Q1: Mounting calls for review of industrial relations practice. This Day Live.

European Commission.(2009). European Competitiveness. Retrieved on 26-05-2016

[http://europa.eu.int/comm/enterprise/maritime/shipbuilding- Market/index.htm/]

Fasolo, E. (2010). Emerging gateways for Italian high tech companies to the Silicon Valley entrepreneurial ecosystem Dynamics, 35(1), 12-31

Field, A. (2009). Discovering statistics using SPSS. Sage publications.

Fiordelli, M., Diviani, N., \& Schulz, P. J. (2013). Mapping health research: A decade of Evolution. Journal of Medical Internet Research, 15(5)

Forbes, (2012). Strategy- without- execution-is hallucination /\#15086c517ea8

https://www.forbes.com/sites/karlmoore/2012/05/31/

Foreman, J., \& Argenti, P. A. (2005). How corporate communication influences strategy implementation, reputation and the corporate brand: an exploratory qualitative study. Corporate Reputation Review, 8(3), $245-264$.

Freeman, R. E. (2010). Strategic management: A stakeholder approach.. Cambridge: University Press.

Gathenya, J., Bwisa, H., \& Kihoro, J. (2012). Entrepreneurial Strategic Planning Practices and Firm Performance among Women-led Small and Medium Enterprises in Kenya. Ph. D thesis, Jomo Kenyatta University.

Ghazzawi, I. (2018). Organizational Decline: A Conceptual Framework and Research Agenda. International Leadership Journal, 37.

Grant, R. M. (2016). Contemporary strategy analysis: Text and cases edition. John Wiley \& Sons. Ltd 
Grill, R. J. (2014). Interpreting the emergence and development of high Technology Electronics industry clusters in selected second tier global regions (Doctoral dissertation).

RoK. (2016). Kenya Economic Outlook. Government of Kenya .

Hambrick, D. C.(2007). Academy of management review, 32(2), 334-343

Hambrick, M. E., Frederick, E. L., \& Sanderson, J. (2015). From yellow to blue: Exploring Lance Armstrong's image repair strategies across traditional and social media Communication \& Sport, 3(2), 196-218.

Hamilton, R.T., \& Shergill, G.S., 1992, The relationship between Strategy-structure fit and financial performance in New Zealand: Evidence of generality and validity with enhanced controls. Journal of Management Studies, 29, 95-113.

Harvard Business School, ISC,.(2018).https://www.isc.hbs.edu/creating-shared- value/ pages/Published-CSVCases.aspx.

Henrik Sornn- Friese. Rene, Taudam, Poulsen, \& Martin Jes, I. (2012). Global Shipping in Small Nations. Nordic Experience, pp 61-99

Henry, S., Raduan, C., Jegak,U., Haslinda, A. \& Alimin,I.(2006). Management, Strategic Management Theories and the Linkage with Organizational Competitive Advantage from the Resource based perspective European journal of Social Sciences, 2(3): 1- 25

Heppler, J. A. (2016). Machines in the Valley: Community, Urban Change, and Environmental Politics in Silicon Valley, 1945-1990. The University of Nebraska- Lincoln.

Higgins, J. M. (2005). The eight 'S's of successful strategy execution. Journal of Change Management, 5(1),3-13.

Hogan, R., \& Kaiser, B. R. (2005). What we know about leadership. Review of General Psychology, 9 (2), $169-180$

Hommel,.U., \& Thomas, H. (2014). Research on business schools: themes, conjectures and future directions. The institutional development of business schools, 6-38.

Hou , \& Goranova. (2017). Does One Size Fit All? Investigating Pay-Future Performance Relationships Over the "Seasons" of CEO Tenure. Journal of Management, 43(3), 864-891.

Huber, F.(2011). Do clusters really matter for innovation practics in Information Technology? Questioning the significance of Technological Knowledge spillovers. Journal of Economic Geography, 12(1), 107-126.

Hrebiriak, .L. (2013).Making Strategy Work: Leading Effective Execution and Change (2nd Ed.) 2013

Isaac, O., Masoud, Y., Samad, S., \& Abdullah, Z. (2016). The mediating effect of Strategic implementation between strategy formulation and organizational performance within government institutions in Yemen. Research Journal of Applied Sciences, 11(10), 1002-1023.

Jonk, J., \& Ungerath, M. (2006). Mergers and acquisitions: Not so fast-companies: Worldwide.

Kaplan, N. D \& . (1996- 2001). Balanced scorecard: Translating strategy into action. Harvard Business School Kaplan,R.S, Norton, .D.P(2004) Strategy maps. Converting intangible assets into tangible Outcomes. Massachusetts: Harvard Business Press; 2004.

Karvonen T, Vaiste J, Hernesniemi, H. (2008). Suomen meriklusteri 2008. Tekes, Helsinki

Katana, E. L. (2018). Determinants of Strategy Execution in Shipping Companies in Kenya Eric Lewa (Doctoral dissertation, COHRED-JKUAT).

Khayota, M. C. (2014). Critical Analysis of Strategy Implementation on Organization Performance in Service Delivery: Case of Lake Victoria South Water Services Board in Kisumu. European Journal of Business and Management, 6(30), 192-201.

Kibicho, P. (2015).Determinants of Strategy Implementation Success in the Insurance Insurance Industry: A Survey of Insurance Companies in Kenya. International Journal of Business and Social Science, 6(4), 74-94.

Kihara, M. P. (2017). Influence of strategy implementation on the performance of Manufacturing small and medium firms in Kenya (Doctoral dissertation, COHRED, JKUAT)

KIPPRA. (2009). Final Report on the Development of Appropriate Commercial Maritime Policies in Kenya. Nairobi: Kenya Maritime Authority. 
KMA. (2015). Kenya’s Prosperity Depends on Getting Right Leadership at Port-Nairobi: Kenya Maritime Authority.

Kothari, C. R. (2012). Research methodology: Methods and techniques. New Delhi: New Age International (P) Limited Publishers.

Kotler, P., \& Lee, N. (2005). Best of breed: When it comes to gaining a market edge While supporting a social cause, "corporate social marketing" leads the pack. Social marketing quarterly, 11(3-4), 91-103.

KPA. (2009). The Authority's Key Achievements. Kenya Ports Authority.

Krueger, J. (2004). “Strategy Implementation Tactics as Response to Organizational, Strategic and Environmental Imperatives". Management Revue, 15, 460 -480

KSAA. (2016). Sector Outlook. Kenya Ships Agents Association. Kenya Ships Agents Association.

Kumar, T. V. (2017). International Collaborative Research "Smart Economy in Smart Cities" and Conclusions of Cities Case Studies. Smart Economy in Smart Cities, pp. 1039- 1086.

Laffort, P. and Martimost, A. (2002). The Hard Side of Strategy Management, HarvardBusiness Review, Harvard Business School Press, October

Lagendijk, A., \& Charles, D. (1999). Clustering as a new growth strategy for regional economies? A discussion of new forms of regional industrial policy in the United Kingdom. Boosting innovation the cluster approach, 127

Lewis, J. L., \& Sheppard, S. R. (2006). Culture and communication: Can landscape Visualization improve forest management consultation with indigenous communities? Landscape and Urban Planning, 77(3), 291-313.

Lewis, M., Brandon-Jones, A., Slack, N., \& Howard, M. (2010). Competing through Operations and supply: the role of classic and extended resource-based Advantage. International Journal of Operations \& Production Management, 30(10), 1032-1058.

Li, Y., Gouhui, S., \& Eppler, M. (2008). Making strategy work: A literature review of influencing strategy implementation. ICA Working Paper 2/2008, Institute of Corporate Communication, Univesita della Svizzera Italiana.

Ling, Y., Simek, Z., Lubatkin, M., \& Veiga, J. (2008). The impact of Transformational CEOs on Performance of Smallto Medium Sized firms: Does organizational context matter? Journal of Applied Psychology, 93(4) 923-934.

Lu, J. W., \& Beamish, P. W. (2006). SME internationalization and Performance; growth profitability. Journal of International Entrepreneurship, 4 (1), 27-48.

MacLennan, A. (2011). Strategy Execution: Translating strategy into action complex Organizations. Abigdon: Routledge.

Mankins, M.,\& Steele, R. (2005). Turning great strategy into great performance. Havard Business Review,.

Marimuthu, M., \& Kolandaisamy, I. (2009). Can demographic diversity in top Management team contribute for greater financial performance? An empirical discussion. Journal of International Social Research, 2(8), $273-286$.

Masinde, P. M. (2017). Effect of strategic management drivers on operational Performance of container terminal: a case study of Kenya ports authority. . Strategic Journal of Business \& Change Management , 4(4).

Mbaka, R. M., \& Mugambi, F. (2014). Factors affecting successful strategy Implementation in the Water Sector in Kenya. Journal of Business and Management, 16(7), 61-68.

Minghui, G. (2013). China The world Largest Shipbuilding after Skyrocketing Growth, Smartcomp Research Report Maritime Cluster, pp.15 (3), .

Mokhele, T. (2015). Creating Maritime Clusters as Strategic Drivers in the Development of The Blue Economy-The African Perspectives \& South African Experience:. Retrieved on 25/04/2015 from http://www.

biznisafrica.co.za/maritime-africa-takes-africas-blue. Economy -to-the next- level/

Montano-Hirose, L. (2009). Organisational models and culture: a reflection from Latin America. European Journal of International Management, 3(2), 146-166.

Monteiro, P., de Noronha, T., \& Neto, P. (2013). A differentiation framework

MOTIF.(2016). State Department for Maritime and Shipping Affairs.

Mugenda, O., \& Mugenda, A. (2008). Research Methods. Quantitative and qualitative Approaches: . Nairobi:: ACTS Press. 
National Oil Of Kenya. (2016). About Us. Retrieved on 26-06 -2016 from

https://www.nationaloil.co.ke/site/3.php?

Nduati, P. N. (2014). Strategy implementation at Kenya accountants and Secretaries National examinations board. Doctoral dissertation, University of Nairobi

Mbaka, R. M., \& Mugambi, F. (2014). Factors affecting successful strategy implementation in the Water Sector in Kenya. Journal of Business and Management, 16(7), 61-68.

Minghui, G. (2013). China The world Largest Shipbuilding after Skyrocketing Growth, Smartcomp Research Report Maritime Cluster , pp.15 (3), .

Mokhele, T. (2015). Creating Maritime Clusters as Strategic Drivers in the Development of the Blue Economy-The African Perspectives \& South African Experience:. Retrieved on 25/04/2015 from http://www.

biznisafrica.co.za/maritime-africa-takes-africas-blue. Economy -to-the next- level/

Montano-Hirose, L. (2009). Organisational models and culture: a reflection from Latin America. European Journal of International Management, 3(2), 146-166.

Monteiro, P., de Noronha, T., \& Neto, P. (2013). A differentiation framework for Maritime Clusters: Comparisons across Europe. Sustainability, 5(9), 4076- 4105

Ndubai, R. E., Mbeche, I. M., \& Pokhariyal, G. P. (2016). A Study of the Relationship among Performance Contracting, Measurement and Public Service Delivery in Kenya.Open Access Library Journal, 3(09), 1

Ng'wanakilala, F. (2013). Tanzania signs port deal with China Merchants Holdings, . Smart Comp Research Report, No 3, Oct 2013 P.74.

Njøs, R., \& Jakobsen, S. E. (2016). Cluster policy and regional development: scale, Scope and renewal. Regional Studies, Regional Science, 3(1), 146-169.

Notteboom, T. \& Rodrique J-P. (2009). The future of containerization: Perspective from Maritime and Inland freight distribution. Geojournal Vol. (1) pp.7 -22

OECD. (2014). Science,Technology and Industry Outlook 2010. OECD, Paris, .

Okwachi, S., Gakure, R., \& Ragui, M. (2013). Business Models-What is their effect on the implementation of strategic plans by SME's, Prime Journal of Business Administration and Management. 3(5) 1025-1032.

Olavarrieta, S., \& Ellinger, A. (2007). Resource- based theory and strategic logistics Research.International Journal of Physical Distribution \&Logistics Management, 27 (9/10), 559-587

Olson, E., Slater, S., Tomas, G., \& Hult, M. (2005). The importance of structure and Process to Strategy implementation. Business Horizons, 48 (1), 47 -54.

Omolo, J. W., Oginda, M. N., \& Oso, W. Y. (2012). Reliability of three Methods of Computer aided thermal pattern analysis. The Journal of the Canadia Chiropractic Association, 51(3), 175.

Omondi, J. D. (2016). A Study on Effects of Performance Contracting Implementation on Service Delivery at Kenya Ports Authority. International Journal of Scientific Research, 4(6), 122.

Oritse, G. (2010). Nigeria, South Africa signs MoU on shipbuilding and repairs, Vanguard publisher.

Orodho, A. J. (2009.). Essentials of educational and social sciences research Methods. Nairobi Masola Publishers, .

Oso, I., \& Onen, C. R. (2009). Qualitative-quantitative research methodology: Exploring the interactive continuum. SIU Press.

Ostrom, E. (2015). Governing the commons. Cambridge university press. Pallis, A. A.,

Parola, F., \& Acciaro, M. (2017). Empirical methods in the study of maritime Economics Volume 19, (2), 189-195 Springer link

Panayides, P. M., \& Wiedmer, R. (2011). Strategic alliances in container liner shipping Research in Transportation Economics, 32(1), 25-38.

Pantouvakis, A., Vlachos, I., \& Zervopoulos, P. D. (2017). Market Orientation for Sustainable performance and the inverted-U moderation of firm size: Evidence from the Greek shipping industry. Journal of Cleaner Production, 165, 705-720.

Papadimitriou, \& Stavroulakis. (2016). The Strategic Factors Shaping Competitiveness For Maritime Clusters. Department of Maritime Studies, University of piraeus Panagiotakopoulos,. 
Pearlson, K. E., Saunders, C. S., \& Galletta, D. F. (2016). Managing and Using Information Systems, Binder Ready Version: A Strategic Approach. John Wiley \& Sons

Peters, T, Waterman, B. (1982). In Search of Excellence: Lessons from American Best run Companies, New York, Harper \& Row: New York

Phipps, K. A., \& Burbach, M. E. (2010). Strategic leadership in the non-profit sector: Opportunities for research. Journal of Behavioral and Applied Management, 11(2), 137

Porter, M. E. (1990). Competitive advantage of nations: creating and sustaining Superior Performance. Simon and Schuster

Porter, M. E. (2011). Competitive advantage of nations: creating and sustaining Superior Performance. Simon and Schuster.

Punniyamoorthy, M. \& R. Mural,. .R.(2010). International Journal of Business Performance Management 2010, vol. 12 , issue $2,103-122$.

Progoulaki, \& Theotokas. (2010). Maritime Cluster. Marine Policy, 34, (3), 575-582.

Qi, H. (2005). Strategy Implementation: The Impact of Demographic Characteristics on the Level of Support Received by Middle Managers. Management International Review, , 45(1), 45-70.

Rajasekar, .J. (2014). Factors Affecting Effective Strategy Industry: A Study of Electricity Distributionc Companies in the Sultanate of Oman. International implementation in a Service. Journal of Business and Social Science, 5(9), 1.

Raps, A., \& Kauffman, D. (2005). Strategy implementation an Insurmountable Obstacle?Handbook of Business Strategy, 6(1):141-146.

Reid, G., C., \& Smith, J. A. (2000). The impact of contingencies on management Accounting system development. Manage. Account. Res., 11(4): 427-450.

Rio Ocean Declaration (2012).

https://globaloceanforumdotcom.files.wordpress.com/2013/03/riooceandeclaration.pdf

Rugman, A. M., \& Verbeke, A. (2008). A regional solution to the strategy and structure of multinationals. European Management Journal, 26(5), 305-313.

Sage, S. (2015). 5 questions to evaluate your implementation strategy. Available On line Retrievedon14/06/2015[http://onstrategyhq.com/resources/strategi-/strategy implementation/]

Salvador, R., Simões, A., \& Soares, C. G. (2016). The economic features, internal structure and strategy of the emerging Portuguese maritime cluster. Ocean \& Coastal Management, , 129, 25-35.

Sánchez, R. J., \& Wilmsmeier, G. (2010). Contextual port development: A theoretical approach. In Essays on port economics (pp. 19-44). Physica, Heidelberg.

Saunders, M. N. (2011). Research methods for business students. 5/e.Pearson Education India.

Schaap, J.I. (2006). „Toward Strategy Implementation Success: An Empirical Study of the Role of Senior-Level Leaders in the Nevada Gaming Industry". UNLV Gaming Research \& Review Journal, 10, 13-37.

Schuster, G., \& Rueck, P. (2017). Innovation diffusion, licensing and corporate entrepreneurship-a conceptual review. International Journal of Entrepreneurship and Innovation Management, 21(1-2), 119-142.

Scott, A. J. (2012). A world in emergence: Cities and regions in the 21st Century. Cheltenham: Edward Elgar.

Sekaran,U. (2006). Research Methods for Business. New York: John Wiley \& Sons

Sekaran, U.(2016).Research Methods for Business.A skill building approach. Sussex, John Wiley \& Sons Ltd, .

Seuring, S., \& Müller, M. (2008). From a literature review to a conceptual Framework for Sustainable Supply chain management. Journal of cleaner production,16 (15), 1699-1710.

Shinn, H. D., \& EisenmSousaan, J. (2012). China and Africa: A century of Engagement. University of Pennsylvania Press, , pp 39-68

Sial, A., Usman, M. K., Zufiqar, S., Satti, A. M., \& Khursheed, I. (2013). Why Do Public Sector Organisations Fail In Implementation of Strategic Plan in Pakistan. Public Policy and Administration Research, 3(1), 222-573.

Simons, J. (2013). Qualitative methods in health research. Methods, 1, 2. SAGE,Publishing.

Sorooshian, S., Norzima, Z., Yusuf, I \& Rosnah, Y., (2010) Effect Analysis on Strategy Implementation Drivers. World Applied Sciences Journal 11 (10): 1255-1261, ISSN 1818-4952 IDOSI Publications. 
Sousa, R., \& Voss, C. A. (2004). Quality management re-visited a reflective Review and agenda for the future research. Journal of operations Management, 20(1), 91-109

Spyropoulou, S., Katsikeas, C. S., Skarmeas, D., \& Morgan, N. A. (2018). Strategic goal accomplishment in export ventures: the role of capabilities, knowledge, and environment. Journal of the Academy of Marketing Science, 46(1), $109-129$.

Stavroulakis, P. J., \& Papadimitriou, S. (2016). The strategic factors shaping Competitiveness for maritime clusters. Research in Transportation Business\&M anagement,19, 34-41.

Steets.J. Steets, J., Grünewald, F., Binder, A., De Geoffroy, V., Kauffmann, D, Krüger, S., \& Sokpoh, B.(2010). Cluster approach evaluation 2 synthesis report. Cluster Approach Evaluation 2nd Phase. Groupe URD and the Global Policy Institute, Apr. 2010.

Sullivan, P. A. (2011). Methods and methodology in composition research:. SIU Press,

Tan, B. S., \& Thai, V. V. (2014). Knowledge sharing within strategic alliance networks and its Influence on firm performance: the liner shipping industry. International Journal of Shipping and Transport Logistics, 5, 6(4), 387411.

Teece, D., G. Pisano and A. Shuen, (1997) Dynamic Capabilities and Strategic Management. Strategic Management Journal, 18 (7), 509-533.

Teece, D. J. (2007). Explicating dynamic capabilities: The nature and micro foundations of (Sustainable) enterprise performance. Strategic Management Journal, 28(13), 1319-1350

Tillema, S., (2015). Towards an integrated contingency framework for MAS sophistication: Case studies on the scope of accounting instruments in Dutch power and gas companies. Manage. Account. Res., 16(1): 101-121.

Tseng, S. M., \& Huang, J. S. (2011). The correlation between Wikipedia and Knowledge sharing on job Performance. Expert Systems with Applications, , 38, 6118-6124

UNCTAD. (2014). Review of Maritime Transport .

UNECA .(2015). United Nations Economic Commission for Africa. Tackling maritime-related issues in Africa. https://www.uneca.org/stories/tackling-maritime-related--issues-africa.

Ural, T., \& Acaravci, S. K. (2006). The effects of firm's strategic factors on export and firm Performance: A comparison of permanent and sporadic exporters. Problems and Perspectives in Management, 4(4), 42-62.

Usman, N. D., Kamau, P. K., \& Mireri, C. (2014). The influence of implementation Phase Principles on project performance within the building industry in Abuja, Nigeria.

Verona, G., \& Ravasi, D. (2012). Unbundling dynamic capabilities: An exploratory study of continuous product innovation. Industrial and Corporate Change, 12(3), 577-606.

Wainaina, J. N. (2014). Strategy implementation and performance of firms in telephony industry in Kenya . Doctoral dissertation, University of Nairobi.

Wessner, C., \& Wolff, A. (2012). Rising to the Challenge: U.S. Washington (DC). innovation Policy for the Global Economy.

Wijholst, N. (2006). Dynamic European maritime clusters (30), . IOS Press.

Winter, S. G. (2013). The satisficing principle in capability learning. Strategic Management Journal, 21(10/11, Special Issue: The Evolution of Firm Capabilities), 981-996.

Wood, M. (2005). The fallacy of misplaced leadership. Journal of Management Studies, 42(6), 1101-1121.

Woods., M. (2009). A contingency theory perspective on the risk management control System within Birmingham City Council. Manage. Account. Res, 20(1): 69- 81

Wright, P. M., Snell, S. A., \& Dyer, L. (2005). New models of strategic HRM in a globalcontext. . The International Journal of Human Resource Management 16(6), 875-881.

Xinhuanet (2013) China's Maritime Industry to Keep Growing. Retrieved on 5.06.2015

[Http://news.xinhuanet.com/english/china/2013-5/20 /c_132395837.htm]

Yamane, T. (1967). Statistics: An introductory Analysis, 2nd Ed. New York: Harperand Row.

Yasuda, T. (2005). Firm Growth, Size, Age and Behavior in Japanese manufacturing, Small Business Economics 24 (1) $1-15$ 
Zahra, S. A., Sapienza, H. J., \& Davidsson, P. (2006). Entrepreneurship and dynamic Capabilities: A review, model and research agenda. Journal of Management Studies, 43(4), 917-955.

Zaribaf, M., \& Hamid, B. (2009). An effective factors pattern affecting implementation of Strategic Plans. Academic and Business Research Institute.

Zeng, D., Mako, W., \& Seward, J. (2009). Promoting Enterprises - Led innovation in China DC: : The World Bank., 2009.

Zhang, W., \& Lam, J. S. L. (2017). An empirical analysis of maritime cluster evolution From the port development perspective-Cases of London and Hong Kong. Transportation Research Part A: Policy and Practice, 105, $219-232$.

Zheng, W., Yang, B., \& McLean, G. N. (2010). Linking organizational, Culture, Structure Strategy,and organizational effectiveness: Mediating role of knowledge management. Journal of Business research, , 63(7), 763-771.

Zhou, K. Z., Li, J. J., Zhou, N., \& Su, C. (2008). Market orientation, job satisfaction, Product quality and firm performance: evidence from China. Strategic Management Journal,, 29(9),

Zumitzavani, V. \& Udchachone, S. (2014). The Influence of Leadership Styles on Organisational Performance Mediated by Organisational Innovation:

A Case Study of the Hospitality Industry in Thailand. International Conference on Economics, Management and Development, 45 


\section{APPENDIX I: KEY MARITIME CLUSTER}

\section{S/}

No KENYA MARITIME CLUSTER

1 Cargo handling, Ports and Infrastructure (Ports - 6, CFSs - 33, \& ICDs -3)

2 Transport Service providers (Trucking firms, Ferries, RVR/SGR)

3 Third Party Logistics providers-3PL (Freight logistics, Shipping lines and warehousing)

4 Complementary (Auxiliary) Serices (Banking \& Insurance services)

5 Blue economy (Maritime Sporting, Cruise tourism, fishing, aquaculture, ship/ferry building andand and coastal mining)

6 Safety, Regulatory and Security (KENHA, KMA, EPZA, KPA, KRA, LCDA, KN and KCGS)

$7 \quad$ Trading \& repairs (oil refinery \& Pipeline)

8 Manufacturing, processing and value addition (processing firms: fish processing, Economic Zones, Exclusive Economic Zone (EEZ), Export Processing Zones

9 Mining and extractives (Minerals; offshore oil/gas - Upstream-(extractive); Exploration and Production (E\& P); Geothermal power, solar power and wind power

10 Institutions (JKUAT, NYS, Bandari college, Pwani University, Utalii College, KMFRI, KPLC, KEMFRI and KWS

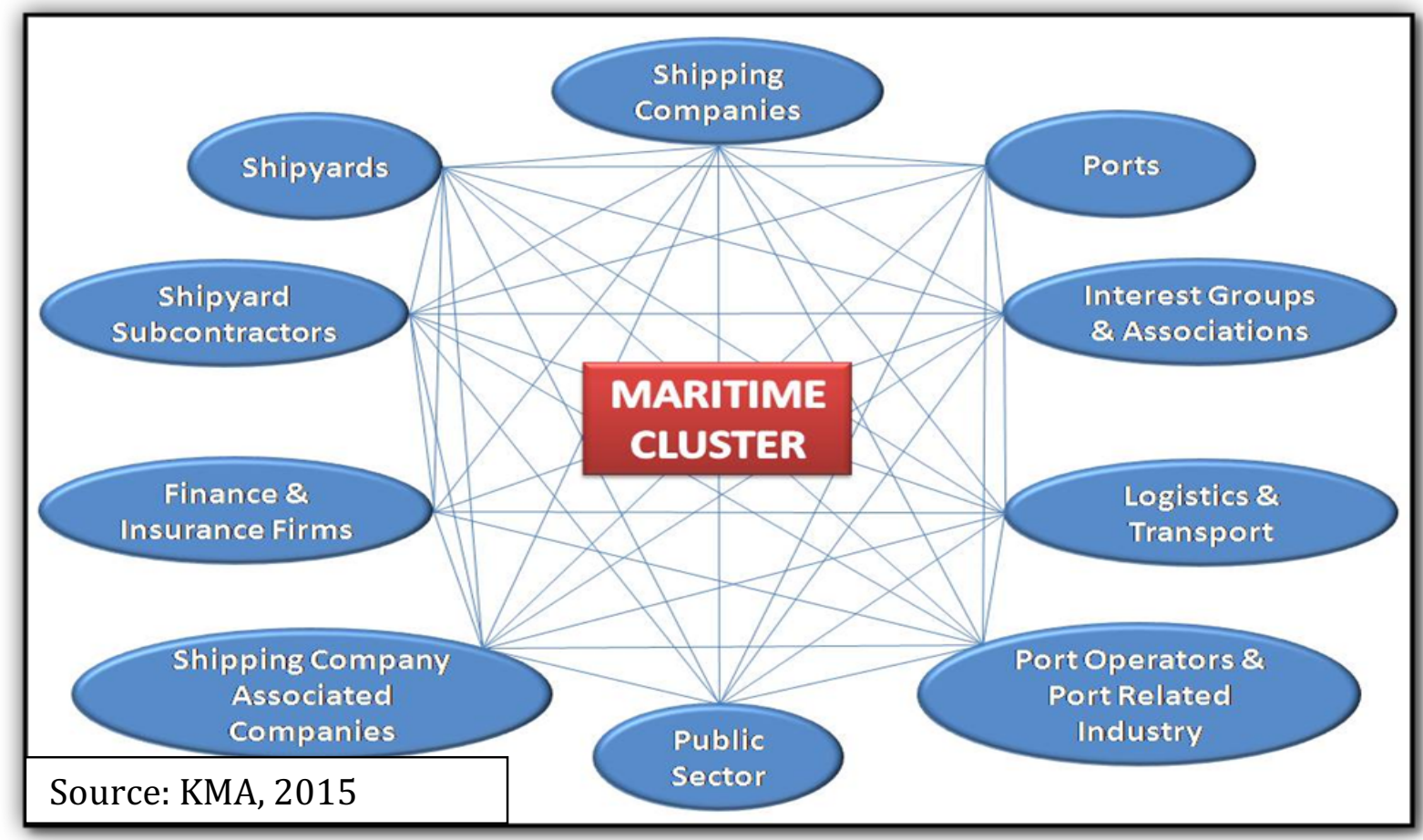

